\title{
Meccanica
}

\section{Ambient vibration testing and structural identification of a cable-stayed bridge --Manuscript Draft--}

Manuscript Number:

Full Title:

Article Type:

Section/Category:

Keywords:

Corresponding Author:

Corresponding Author Secondary Information:

Corresponding Author's Institution:

Corresponding Author's Secondary Institution:

First Author:

First Author Secondary Information:

Order of Authors:

\begin{tabular}{|l} 
\\
\hline Order of Authors Secondary Information: \\
\hline Funding Information: \\
\hline Abstract:
\end{tabular}

Ambient vibration testing and structural identification of a cable-stayed bridge

\section{S.I. : Nonlinear Dynamics, Identification and Monitoring of Structures}

Solids

Ambient vibration tests; cable-stayed bridges; structural identification; finite element models.

Antonino Morassi, Civil Engineering; Mathematics

University of Udine

Udine, Udine ITALY

(

The paper presents the results of an experimental and theoretical investigation on the Pietratagliata cable-stayed bridge (Udine, Italy). Ambient vibration tests were performed in order to estimate the dynamic characteristics of the lower vibration modes of the bridge. Structural identification is carried out by means of a manual tuning procedure based on finite element models of increasingly accuracy. The analysis allows to improve the description of boundary conditions and mechanical interaction between the bridge components. Results from local dynamic testing are used to estimate the traction on the cables and to assess the integrity of the suspending system of the bridge. 
1

2

3

4

5

6

7

8

9

10

11

12

13

14

15

16

17

18

\title{
Ambient vibration testing and structural identification of a cable-stayed bridge
}

\author{
Chiara Bedon • Michele Dilena • Antonino Morassi
}

Received: December 30, 2015 / Accepted: date

\begin{abstract}
The paper presents the results of an experimental and theoretical investigation on the Pietratagliata cable-stayed bridge (Udine, Italy). Ambient vibration tests were performed in order to estimate the dynamic characteristics of the lower vibration modes of the bridge. Structural identification is carried out by means of a manual tuning procedure based on finite element models of increasingly accuracy. The analysis allows to improve the description of boundary conditions and mechanical interaction between the bridge components. Results from local dynamic testing are used to estimate the traction on the cables and to assess the integrity of the suspending system of the bridge.
\end{abstract}

Keywords Ambient vibration tests - Cable-stayed bridges - Structural Identification - Finite Element Models

\section{Introduction}

The design of suspension and cable-stayed bridges requires accurate finite element modelling for the prediction of response to loads, such as wind, traffic or earthquake $[2,6-8,11,12,17]$. This aspect is of particular importance for long-span bridges for which the estimate

\section{Bedon}

Dipartimento di Ingegneria e Architettura, Università degli Studi Trieste, piazzale Europa 1, 34127 Trieste, Italy

E-mail: bedon@dicar.units.it

M. Dilena · A. Morassi

Dipartimento di Ingegneria Civile e Architettura, Università degli Studi di Udine, via Cotonificio 114, 33100 Udine, Italy E-mail: michele_dilena@email.it

A. Morassi (corresponding author)

E-mail: antonino.morassi@uniud.it of the critical flutter velocity (sensitive to the relationship between the natural frequencies of the first vertical mode and the torsional modes) is crucial. However, even the dynamic analysis of cable-stayed bridges of small/medium size is of great practical interest: firstly, because these infrastructures are quite common and are of strategic importance in emergency situations; secondly, because accurate numerical models for mediumsmall bridges are rather difficult to develop, as the dynamic response is influenced by a large set of structural details that are usually less important for large bridges. In fact, long span cable-stayed bridges can be very often modelled by slender beam elements with equivalent cross-section properties, whereas more sophisticated models are needed to capture the dynamic behavior of small bridges. Modelling of small/medium size bridges is usually sensitive to the description of boundary conditions and internal constraints, to construction details and constitutive equations of materials $[4,9,10]$.

This paper discusses some of the above aspects with reference to a cable-stayed bridge whose suspended span is 67 meters long. An experimental and theoretical analysis was developed to study the dynamic behavior of the bridge. Ambient vibration tests (AVT) were conducted allowing the identification of the lower vibration modes via operational modal analysis (OMA) techniques. AVT and OMA are powerful tools for the determination of the modal parameters (i.e., natural frequencies and mode shapes) of full-scale bridges. Dynamic testing, in fact, does not interfere with the normal service of the structure and the methodology turns out to be particularly advantageous for flexible systems, such as large suspension bridges, cable-stayed bridges or arch bridges, for which the environmental vibrations can excite a significant number of principal modes belonging to the low frequency range. 
The analysis developed in the first part of the paper demonstrates how a significant improvement in the match between modal parameters from a finite element model and measured data can be achieved using logical steps and justified modifications to update an initial numerical model of the bridge. The analysis also shows that the development of a sophisticated finite element model of the bridge entails a significant computational burden due to the numerical description of some structural details, such as, the boundary conditions at the base of the pylons of the tower and at the ends of the main longitudinal girders, and the connections between the cables and the tower/deck structures. In the second part of the paper, local natural frequencies of the stay cables estimated from ambient vibration tests were used to identify the axial force on the cables. The accurate finite element model of the bridge was used to assess the effects of potential collapse of one or two cables for structural health monitoring purposes. The analysis shows that natural frequencies are not particularly sensitive to these structural modification. On the contrary, damage induces appreciable changes in the shape of the lower vibration modes of the bridge, suggesting a potential use of this information for diagnostic purposes.

\section{Description of the bridge}

The bridge consists of a steel-concrete composite deck simply supported at the ends, a system of double-plane cables supporting the deck, and an inclined steel tower, see Figure 1. The total length of the deck is $67 \mathrm{~m}$. The bridge width is $11.10 \mathrm{~m}$, including two lanes $3.50 \mathrm{~m}$ in width each and two lateral footways.

The deck structure consists of Predalles concrete panels and a reinforced concrete (RC) slab, $0.25 \mathrm{~m}$ in thickness, supported by two lateral steel girders and a longitudinal central beam. Longitudinal girders are connected to the transverse beams by means of bolted joints. Lateral and transverse longitudinal girders have double-T cross-section, 1.27 and $1.20 \mathrm{~m}$ high respectively, while a smaller cross-section (HEB500 type) is used for the central longitudinal girder. The RC slab is connected to the upper flange of the longitudinal girders by means of welded steel stud connectors (diameter $20 \mathrm{~mm}$ and height $200 \mathrm{~mm}$ ).

The bridge deck is supported at the ends on a $\mathrm{RC}$ pier on the National Route (NR) n.13 side (total height $12 \mathrm{~m}$ and square hollow cross-section, with $3 \mathrm{~m}$ the edge size and $0.40 \mathrm{~m}$ the nominal thickness) and on a cast-in-place RC foundation block on the Pietratagliata side, see Figure 2. On the NR n.13 side, the position of the pier is slightly asymmetrical with respect to the longitudinal axis of the bridge (see detail (a) in Figure 2 ), and two unidirectional bearing supports are used to sustain the lateral deck girders. On the Pietratagliata side, conversely, the lateral girders are restrained by means of cylindrical hinges. In addition, the deck is supported by three equally spaced groups of forestays on the upstream and downstream side. Each group consists of four Dywidag bars (Gewi St555/700 type, $63.5 \mathrm{~mm}$ in diameter) which are connected to the main girders by means of special metal devices (see Figure 2). The length of these forestays ranges between $20.50 \mathrm{~m}$ and $49.10 \mathrm{~m}$ (Figure 1). Further backstays, about $22.50 \mathrm{~m}$ long, connect the steel tower to a RC foundation block built on the rock. The tower consists of two inclined columns, having thin-walled circular cross-section 1.10 $\mathrm{m}$ in diameter (thickness $20 \mathrm{~mm}$ ). The connection between the inclined columns is given by two thin-walled tubes, $0.50 \mathrm{~m}$ in diameter (thickness $15 \mathrm{~mm}$ ), horizontally positioned at approximately $17 \mathrm{~m}$ and $21 \mathrm{~m}$ of elevation from the deck. As in the case of the girders support on the Pietratagliata side, special restraints are realized at the base of the steel tower in order to reproduce the effect of cylindrical hinges.

The construction of the bridge was completed in 2007 and the infrastructure was opened to traffic in 2008. Ambient vibration tests were carried out in July 2009.

\section{Dynamic testing}

\subsection{Preliminary Finite Element Model}

With the aim of planning the experimental campaign, a preliminary 3D Finite Element (FE) model of the bridge was implemented using the SAP2000 structural software package (version 9.1) [13]. The geometry and material properties of the FE-model were determined by using nominal dimensions and technical data derived from design reports and drawings, as well as experimental tests on samples. The main assumptions of the preliminary FE-model (denoted by M01-A) were as follows:

1. The RC deck was modeled using 4-nodes shell elements, with 6 degrees of freedom (DOFs) at each node. The effect of steel reinforcement and cracking of the RC slab was neglected.

2. Longitudinal and transverse girders were modeled by means of $3 \mathrm{D}$ frame elements.

3. Vertical rigid links were used to connect the shell elements of the RC slab and the corresponding nodes of the longitudinal and transverse frame elements (steel girders). Due to this assumption, no relative displace- 
ments and rotations were allowed between corresponding nodes.

4. Stays were described by means of $3 \mathrm{D}$ truss elements hinged at the ends. To represent a single group of four cables, an equivalent cross-section was taken into account. Additional lumped masses were introduced at each truss end to consider the inertia of cables.

5 . The bracing system placed on the top and bottom side of the bridge deck was also included in the model (see Figures 1 and 2). Double L-shaped angular profile brace members were described by means of frame elements hinged at the ends.

6. The RC pier on the NR n.13 side was replaced with ideal supports (see point 8 ).

7. Regarding the mechanical characterization of concrete and steel, isotropic linearly elastic constitutive models were taken into account. Experimental test on cylindrical cores provided an average Young's modulus of the concrete of the deck slab equal to $E_{c}=42$ $G P a$. The Young's modulus and weight for unit volume of steel were assumed $E_{s}=206 \mathrm{GPa}$ and $78.5 \mathrm{kN} / \mathrm{m}^{3}$. The Poisson's ratio of concrete and steel was set equal to 0.2 and 0.3 , respectively. A weight per unit volume of $25 \mathrm{kN} / \mathrm{m}^{3}$ was assumed for RC structural members. On the deck slab, an additional weight per unit area of $0.37 \mathrm{kN} / \mathrm{m}^{2}$ and $0.50 \mathrm{kN} / \mathrm{m}^{2}$ was also considered to account for the effects of the asphalt pavement and walkways, respectively.

Careful consideration was paid to the description of deck and tower restraints. In particular:

8. The unidirectional bearing devices at the girders ends on the NR n.13 side were described in the form of simply supports, able to allow displacements along the traffic direction and rotations of the deck around its perpendicular axis.

9. The end girders restraints on the Pietratagliata side were modelled as cylindrical hinges, whose axes are perpendicular to the traffic direction. Similar restraint was introduced at the base of the steel tower pylons.

Modal analysis on the preliminary M01-A FE-model employed an unloaded configuration of the bridge, that is eigenvalue analysis was carried out by fully neglecting the overall non-linear behaviour due to the geometry change induced by the deformation of the cables under static dead loads. This analysis will be referred as linear modal analysis. Results are summarized in Figure 3 , in the form of natural frequencies and corresponding mode shapes. The first twelve vibration modes include modes dominated by vertical oscillation of the deck under bending (type 'B', e.g., modes $1,3,6,8,12$ ) or torsional ('T', modes $2,4,5,7,9)$ vibration. Few modes are mainly associated to oscillation of the pylon ('P', modes 10 and 11). It turns out that lower modes are generally well separated in frequency.

\subsection{Instrumental layout and experimental procedure}

Dynamic testing was carried out with the aim of identifying the low vibration modes of the bridge. Although the traffic on the bridge was rather scarce during testing (five-six cars per hour, approximately), tests were performed under the strict requirement of the Pietratagliata Municipal Authority that the operations would have not provided interference with service. By the above reason, no additional excitation (e.g., due to car/cars crossing the bridge, as it is usual for small-medium bridges studied via OMA techniques) was included to increase the signal-to-noise ratio, and almost pure ambient vibration testing was adopted to determine the dynamic characteristics of the bridge. This working assumption resulted in additional difficulty for the experimental analysis and interpretation of test measurements, as discussed in the sequel.

The instrumentation chain was based on a 16-channels data acquisition system, connected to a remote personal computer. The sensors consisted in 11 Sprengnether mono-axial servo-accelerometers operating in the frequency range 0-25 Hz. Each sensor was provided with a pre-amplifier having variable gain controlled by the remote computer. The signal was transmitted in differential modality to the acquisition system, where it was converted in single-ended modality to be filtered and passed to a 16 -bit $\mathrm{A} / \mathrm{D}$ converter.

Based on the modal analysis carried out on the preliminary M01-A FE-model of the bridge, the instruments were located at 20 selected points, 16 on the deck and 4 on the tower, as shown in Figure 4. Two setups were separately taken into account during the experiments. In setup $S 01$, the vertical acceleration at pairs of opposite points in five transverse cross-sections of the bridge deck and at the support on the National Route n. 13 was monitored. Considering two sensors as reference transducers, setup $S 02$ allowed to complete the characterization of the vertical response of the deck and to measure the response at four points of the tower.

Time acquisition during tests was equal to $45^{\prime}$, corresponding to about 1600 times the period of the fundamental vibration mode of the bridge. The sampling rate used during acquisition was $400 \mathrm{~Hz}$. During postprocessing analysis, the signal data were further decimated in time by a factor 10, giving a baseband for the analysis ranging till to $20 \mathrm{~Hz}$. 
3.3 Experimental results and a comparison with the preliminary $M 01-A$ FE model

Natural frequencies, damping ratios and mode shape components were estimated by means of the Enhanced Frequency Domain Decomposition (EFDD) technique [5] and of the Stochastic Subspace Identification (SSI) technique [15], both available in the software package ARTeMIS [14]. As an example, Figure 5a shows the singular values of the spectral matrices of all data sets. It can be seen that, in spite of the small amplitude of the ambient excitation, the peaks of the singular values associated to the first six lower vibration modes clearly emerge above the noise level. Besides the global principal modes, other peaks appear in the neighborhood of $1.3 \mathrm{~Hz}$ and in the frequency ranges $2.1-2.5 \mathrm{~Hz}$, 3.7-4.3 Hz and 6.3-6.8 Hz. Most of these peaks correspond to the lower modes of the stay cables, as it will be discussed in Section 5. For the sake of completeness, Figure 5b shows the stabilization diagram obtained by applying the Stochastic Subspace Identification (SSI) technique to the data coming from the measurement points placed on the deck in setup $S 02$.

Several repeated identifications were carried out separately, either on the same data-set or on partial data and using different baseband, in order to improve the estimate of the observable vibration modes. Modal parameters extracted by the two techniques resulted in good agreement, with few exceptions for damping ratios. Therefore, in the sequel reference is made to estimates obtained by the EFFD technique.

Table 1 collects natural frequency values and damping factors, both obtained as mean value from the various power spectral density output measurements. Deviations of natural frequency estimate from the mean value generally resulted negligible, both in absolute and relative terms. Damping ratios typically resulted less than 1 per cent, with significant deviation from the mean value, especially for Mode 1 . In the majority of the situations encountered during the analysis, the complex character of the identified modes was negligible, with mode components well approximated by real values. Six vibration modes were completely identified. Detailed representation of the corresponding mode shapes is shown in Figure 6.

Visual comparison and MAC criterion [3] allowed to determine the correspondence between experimental (OMA) and analytical (FEA) modes obtained from the preliminary M01-A FE Model of the bridge. A correspondence between OMA modes 1,2,3,4,5,6 and FEA modes 1,2,3,7,6,9 was found, with MAC values (calculated by taking into account the vertical displacements of the deck and the pylon displacements) generally com- prised between 99.6 and 89.3. Despite the rather good correlation between the normalized vibration modes depicted in Figure 6, large discrepancy was found in term of natural frequency values (see Table 1), up to $13 \%$ and $16 \%$ for bending and torsional modes, respectively. Based on the preliminary comparison collected in Table 1 , model updating and refinement was thus undertaken.

\section{FE-model updating}

\subsection{A simplified FE model}

In a first step of the model updating process, the effect of changes on the boundary conditions of the bridge deck were considered. Modifications were implemented directly in the original M01-A FE-model, so preserving the computational efficiency of the analysis. Basing on the modelling assumptions listed in Section 3.1 and taking into account the effective constraints of the bridge (see Figures 1 and 2), the boundary restraints of the lateral deck girders were replaced by clamps on the Pietratagliata side. Moreover, the longitudinal displacement of the supports on the National Route n.13 side was restrained. This model is denoted as M01-B. As shown in Table 2 , the modifications typically resulted in an improvement of natural frequency estimations, thus suggesting the fundamental role of a proper description of the mechanical interaction between the main structural components of the bridge.

\subsection{A refined FE-model}

The role of boundary conditions and internal constraints was fully investigated in the second stage of the model updating process by working on a more detailed FE model of the Pietratagliata Bridge. The refined FEmodel, denoted as M02 in the sequel, was implemented by means of the ABAQUS/Standard computer package [1]. Careful consideration, in this case, was paid to the geometrical description of the bridge components (e.g., deck, pylon, cables and pier), as well as to their reciprocal interaction (Figure 7). 4-node stress/displacement shell elements with reduced integration and large-strain formulation (S4R type available in the ABAQUS element library) were used for the description of the bridge deck and the steel tower, for a total amount of 82,000 and 29, 000 shell elements, respectively. In order to reproduce the nominal geometry and provide refined description of the main structural details, a free meshing technique was used, with average size of shell elements equal to $l_{m}=0.15 \mathrm{~m}\left(0.015<l_{m}<0.3 \mathrm{~m}\right)$ and $l_{m}=0.08 \mathrm{~m}\left(0.01<l_{m}<0.17 \mathrm{~m}\right)$ for the deck 
and the pylon, respectively. A nominal thickness was assigned to these shell elements, lying on the middle plane of each bridge component. In the case of the deck, the structural interaction between the concrete slab and the longitudinal girders (e.g., where steel stud connectors are used) was described by means of tie constraints able to account for a rigid connection between the corresponding DOFs, along the bridge length (e.g., null relative displacements were imposed at the interface between the top flange of the girders and the corresponding mesh nodes belonging to the concrete slab). Beam elements (B31 type) with nominal geometrical properties were used for the double-L shaped metal bracings. Additional lumped masses, representative of the selfweight of these bracings, were applied at the ends of the beam elements. Lumped masses distributed among the concrete slab of the deck were also used to take into account the self-weight of the asphalt layer and the lateral footways.

The steel cables, separately described in their 6 groups, consisted in beam elements (B31 type) with nominal cross-sectional area $(63.5 \mathrm{~mm}$ in diameter) and overall length derived from technical drawings. Lumped masses representative of half the self-weight of the cables were applied at the ends of each beam element. The cables were then connected to the steel tower and to the deck respectively by means of join connectors able to restrain possible relative displacements between the interested nodes. Careful consideration was paid to the geometrical description of the metal supports and devices (see Figure 7, details A, B, and Figure 8), so that local deformations and improper effects could be avoided.

Deck and pylon were then properly restrained. In the case of the pylon (Figure 7, detail C, and Figure 9 ), the metal devices at its base consisted in two inclined steel plates (80 $\mathrm{mm}$ in thickness) properly constrained, so that the typical base support could behave as a cylindrical hinge with respect to a local reference system (free $r_{y^{\prime}}$ rotations, see Figure 9). A master node equally spaced from the centers of the two circular holes and rigidly connected to the ground was assumed as the origin of the local reference system $\left(x^{\prime}, y^{\prime}, z^{\prime}\right)$. Possible distortions of the two steel plates were prevented by implementing kinematic constraints able to kept fix the relative distance between their respective nodes (along direction $y^{\prime}$ ). Analogous modelling approach was used for the description of the deck restraints of the longitudinal lateral girders on the $\mathrm{RC}$ abutment on the Pietratagliata side, see detail $D$ in Figure 7, and Figure 9 .

The RC pier on the NR n.13 side was modelled by $3 D$ solid finite elements. Mesh size refinement required by the geometrical features of the pier (see box of Figure
7) resulted in 48,000 solid elements with average length $l_{m}=0.2 \mathrm{~m}\left(0.06<l_{m}<1 \mathrm{~m}\right)$. Possible soil-to-pier interaction was fully neglected, and the pier was rigidly connected at its base $\left(u_{x}=u_{y}=u_{z}=0\right)$.

Careful attention was finally paid to the description of the mechanical interaction between the bridge deck and the RC pier (Figure 7, detail E). The unidirectional devices were described by means of slot connectors able to provide null relative displacements along the transverse and vertical bridge directions, between the connected nodes $\left(u_{y}=0\right.$ and $u_{z}=0$, in the global reference system shown in Figure 7 ). On the contrary, longitudinal $u_{x}$ displacements and relative rotations $\left(r_{x}, r_{y}, r_{z}\right)$ between the interested nodes were kept unrestrained.

Concerning the characterization of materials, both concrete and steel were assumed to behave linear elastically, with mechanical properties derived from the preliminary FE-models M01-A and M01-B.

Globally, the so implemented M02 FE model resulted in 700,000 DOFs and 160,000 elements. The eigenvalue analysis was developed as follows. A static incremental nonlinear analysis under the effects of the bridge self-weight and dead loads (e.g., footways and asphalt layer) was preliminary carried out on the M02 FE model (Step I) in order to determine the equilibrium reference configuration. In the subsequent Step II, vibration modes were predicted by means of linear modal analysis around the reference configuration derived in Step I. The nonlinear approach used in Step I typically showed negligible modifications in the eigenvalue predictions compared to modal analysis results derived from a fully linear procedure (e.g., neglecting the geometrical change of the configuration induced by the weight of the bridge). Average discrepancy of about $0.6 \%$ was found for the majority of the first 20 natural frequencies. Maximum discrepancies between the nonlinear and the linear procedure were found for few resonant frequencies only, with maximum deviations up to $4 \%$ for higher modes associated to local vibration of the tower. As a result, the nonlinear solving approach was assumed as the reference one for further numerical investigations.

The high modeling and computational cost of the M02 FE model, the geometry refinement of the bridge components as well as their reciprocal interaction generally resulted in dynamic estimations in rather close agreement with test measurements. Table 2 proposes a comparison of OMA, M01-B and M02 natural frequencies, and corresponding MAC values.

The primary effect of the M02 FE model was represented by the prediction of the fundamental vibration mode at $1.599 \mathrm{~Hz}$, not foreseen by the preliminary M01-A and M01-B FE models. The corresponding 
mode shape is characterized by torsional motion of the deck and large deformation of the steel tower (Figure 10). The presence of this vibration mode was also confirmed by further interpretation of test measurements (mode OMA 0 in Table 2). While the singular value curves of the spectral density matrix did not show the presence of this first torsional mode, probably since the corresponding natural frequency is very close to the fundamental flexural one (OMA 1), in a subsequent phase the modal parameters were separately estimated in the frequency domain, for the half-sum and half-difference of the recorded time histories of the deck measurement points, see Figures 11(a) and (b). Based on the vertical oscillations of two control points located on the opposite sides of the same transverse deck cross-section, this approach allows to distinguish bending modes from torsional modes. In fact, if a vibration mode is mainly flexural, the measured amplitude oscillation at the selected pair of control points are similar, and their difference is small. The half-sum of time histories, consequently, magnifies the presence of vertical bending modes and hides the peaks corresponding to torsional ones. Conversely, if a mode is mainly torsional, the vertical modal components at the same control points are similar in amplitude, but have opposite sign, so their sum is small. The half-difference of the corresponding time histories, as a result, automatically excludes the peaks associated to bending modes. By applying this technique to the available experimental measurements it was possible, based on the half-difference of the experimental responses, to identify the peak in the singular value curves of the spectral density matrix corresponding to the 0th OMA mode, see Figure 11(b).

In addition to pointing out the presence of the fundamental vibration mode at $1.599 \mathrm{~Hz}$, the numerical simulations carried out on the M02 FE model generally highlighted the importance of refined geometrical description of few, but crucial, bridge components. Specifically, the proper geometrical and mechanical characterization of the bridge supports (details C and D of Figure 7) and the stays-to-deck and stays-to-pylon connections. On the other hand, however, the progressive increase of the modelling complexity required the solution of a series of additional uncertainties and numerical instabilities. Some of these cases are discussed in the sequel. As a first example, an improper or partial description of the connection detail between some bridge components typically caused the occurrence of higher local vibration modes (e.g., in the range comprised between 6 and $9 \mathrm{~Hz}$ ). These modes are mainly characterized by local distortions either near the staystower and stays-deck connections (Figure 8) or close to the deck and to the steel tower end restraints on the Pietratagliata side (Figure 9). The occurrence of local distortion phenomena was fully prevented by means of an accurate and computationally expensive description of the connection details, based on the technical drawings of the bridge, able to physically reproduce the desired restraint condition between the bridge components. Examples are proposed in Figure 8(a), where the optimized stays-tower connection is compared with a geometrically simplified, but improper connection. The same modelling approach was applied to the staysgirders connection systems (see Figure 8(b)), where local deformations were fully prevented by taking into account the nominal geometry of the steel supporting device and including all the stiffening elements in the model.

Concerning the restraint supports, the resonant frequency of the first vibration mode of the bridge highlighted a marked sensitivity to the deck and pylon base restraints (Figure 9), hence requiring a computational expensive geometrical modeling. The absence of the small steel stiffeners at the base of the steel tower (detail of Figure 9), for example, resulted in underestimation up to $25 \%$ the optimal frequency value of OMA mode 0 . Similarly, the presence of the RC pier, involving an asymmetry in the overall geometry, also resulted in additional difficulties for the optimal correlation between the OMA and FEA vibration modes of the bridge. The main effect of the correct description of the pier geometry highlighted the presence of vibration modes pairs (e.g., typically bending modes of the deck), characterized by comparable in-phase or out-of-phase motion of the deck and bending deformation of the $\mathrm{RC}$ pier, corresponding to almost identical natural frequencies. This is the case, for example, of FEA modes 4 and 5 . In all these circumstances, the correlation between OMA and FEA modes was based on minimization of natural frequency discrepancy values and MAC factor.

Finally, despite the very good correlation between OMA and FEA frequencies, it should be noted that rather scarce MAC values were found in some circumstances. This is the case of higher vibration modes (e.g., OMA mode 5 in Table 2 and the corresponding M02 mode 8 ) characterized by significant motion of the deck coupled with large deformation of the steel tower. Due to few available experimental measurements, modal correlation was undergone in this case by taking into account not only the natural frequency and the calculated MAC value, but also an additional visual correlation. Overall, good agreement between OMA and M02 predictions justified the fundamental role of the sophisticated FE-model, especially for future, possible diagnostic applications. 


\section{Dynamic determination of the axial force on stay cables}

\subsection{Test measurements and their interpretation}

A series of ambient vibration measurements were carried out on all the cables supporting the deck, with the final goal of estimating the axial force acting on them. Dynamic tests were performed by collecting the transverse acceleration time-history of each cable on the vertical plane, at control points placed approximately at the lower third of each cable. Time series of $1200 \mathrm{~s}$ were recorded in each experiment. Cable natural frequencies were identified by computing the auto-spectrum of the acquired acceleration signals. Time series were lowpass filtered and decimated before computing the autospectrum via the modified periodogram method [16], for a resulting frequency resolution of about $5 / 100 \mathrm{~Hz}$.

The analysis of the spectral plots obtained for the cables clearly highlighted the first six natural frequencies of each cable. Table 3 collects the average values of natural frequencies for each group of four cables, on the downstream (D) and upstream (U) side, respectively.

A preliminary analysis of the identified frequencies allowed to conclude that the longer cables (e.g., belonging to groups $1 \mathrm{D}$ and $1 \mathrm{U}$ ) slightly deviate from the ideal taut string model. All the measured natural frequencies of these cables resulted in fact close to integer multiples of their fundamental frequency, with deviations at most equal to $3 \%$ for higher order frequencies. A slightly worst agreement was found for cables belonging to groups $2 \mathrm{D}$ and $2 \mathrm{U}$, with percentage deviations around $5-6 \%$. The need of a more sophisticated mechanical model of cable for the shortest stays belonging to groups $3 \mathrm{D}$ and $3 \mathrm{U}$, finally, was clearly suggested by deviations from the ideal taut string up to $16 \%$ for the 5 th and 6 th frequencies.

Each cable was modelled as a pinned-pinned uniform straight elastic beam subject to an (unknown) axial force $T, T>0$. The small, undamped, in-plane bending free vibrations of the beam with radian frequency $\omega$ are governed by the eigenvalue problem

$\left\{\begin{array}{l}y^{\prime \prime \prime \prime}-2 \alpha y^{\prime \prime}-\beta y=0, \quad \text { in }(0, L), \\ y(x)=y^{\prime \prime}(x)=0, \quad \text { at } x=0 \text { and } x=L,\end{array}\right.$

where $(\cdot)^{\prime}=\frac{d(\cdot)}{d x}$ and

$2 \alpha=\frac{T}{E I}, \quad \beta=\frac{\rho \omega^{2}}{E I}$.

In the above equations, $E=206 \mathrm{GPa}$ is the Young's modulus of the material; $\rho=24.86 \mathrm{~kg} / \mathrm{m}$ is the mass density per unit length; $I=7.981 \cdot 10^{-7} \mathrm{~m}^{4}$ is the moment of inertia of the cross-section of the beam with respect to a principal axis; $L$ is the length of the beam. The general solution to (1) is

$$
\begin{array}{r}
y(x)=c_{1} \sin \left(p_{2} x\right)+c_{2} \cos \left(p_{2} x\right)+ \\
+c_{3} \sinh \left(p_{1} x\right)+c_{4} \cosh \left(p_{1} x\right),
\end{array}
$$

where the positive numbers $p_{1}, p_{2}$ are

$p_{1}=\sqrt{\alpha+\sqrt{\alpha^{2}+\beta}}, \quad p_{2}=\sqrt{\sqrt{\alpha^{2}+\beta}-\alpha}$

and the vector $\mathbf{c}=\left(c_{1}, c_{2}, c_{3}, c_{4}\right) \in \mathbb{R}^{4} \backslash \mathbf{0}$ satisfies

$\mathbf{M}(\omega, T) \mathbf{c}=\mathbf{0}$,

with

$$
\begin{aligned}
& \mathbf{M}(\omega, T)= \\
& \left(\begin{array}{cccc}
0 & 1 & 0 & 1 \\
0 & -p_{2}^{2} & 0 & p_{1}^{2} \\
\sin \left(p_{2} L\right) & \cos \left(p_{2} L\right) & \sinh \left(p_{1} L\right) & \cosh \left(p_{1} L\right) \\
-p_{2}^{2} \sin \left(p_{2} L\right) & -p_{2}^{2} \cos \left(p_{2} L\right) & p_{1}^{2} \sinh \left(p_{1} L\right) & p_{1}^{2} \cosh \left(p_{1} L\right)
\end{array}\right) .
\end{aligned}
$$

The linear system (5) has non-trivial solutions if and only if $\omega$ satisfies the frequency equation

$\operatorname{det} \mathbf{M}(\omega, T)=-\left(p_{1}^{2}+p_{2}^{2}\right)^{2} \sin \left(p_{2} L\right) \sinh \left(p_{2} L\right)=0$,

that is

$p_{2}=\frac{n \pi}{L}, \quad n=1,2, \ldots$

By (4) and (8), the $n$th frequency $\omega_{n}$ has the closed form expression

$\omega_{n}(T)=\frac{n \pi}{L}\left(\frac{E I}{\rho}\left(\frac{n \pi}{L}\right)^{2}+\frac{T}{\rho}\right)^{\frac{1}{2}}, \quad n=1,2, \ldots$,

and, inverting (9), we have

$T=\frac{\rho \omega_{n}^{2}}{\left(\frac{n \pi}{L}\right)^{2}}-E I\left(\frac{n \pi}{L}\right)^{2}, \quad n=1,2, \ldots$

Formula (10) shows that the axial force $T$ can be uniquely determined from the knowledge of a single natural frequency $\omega_{n}$, provided that $L, \rho, E I$ are known quantities. In order to determine $T$, a reasonable choice is to use the fundamental frequency $\omega_{1}$, for which the experience suggests that a better agreement between theoretical and experimental/actual value is expected. However, the estimate of the fundamental frequency may be affected by experimental errors and, moreover, the fundamental frequency is the most sensitive to the boundary conditions that, in the present case, were assumed corresponding to the ideal case of pinned ends. Therefore, with the aim of improving the estimate of the axial force $T$, a least-squares-like procedure was 
implemented. More precisely, for each cable, the error function

$\psi_{N}(T)=\sum_{n=1}^{N}\left(1-\frac{f_{n}^{\text {theor }}(T)}{f_{n}^{\text {exp }}}\right)^{2}$

was introduced, where $f_{n}^{\text {exp }}=\frac{\omega_{n}^{\text {exp }}}{2 \pi}, f_{n}^{\text {theor }}=\frac{\omega_{n}^{\text {theor }}}{2 \pi}$ are the $n$th experimental and theoretical frequency of the cable, and $N$ is the number of first frequencies considered in identification, $N=1, \ldots, 6$. For each $N$, the optimal value of the axial force $T_{o p t}^{N}$ was then determined as

$\psi_{N}\left(T_{o p t}^{N}\right)=\min _{0<T<T_{R d}} \psi_{N}(T)$,

where $T_{R d}$ is yield value of the axial force. A standard gradient-descent based algorithm was used to solve numerically (12) by adopting the estimate of $T$ obtained from the fundamental frequency measurement as initial point in minimization.

Results are collected in Tables 4 and 5. The optimal value of the axial force on each of the four cables composing the groups 1,2 and 3, on downstream and upstream sides, is collected in Table 4. Generally speaking, the values $T_{o p t}^{N}$ are rather stable with respect to $N$. With the exception of the estimate obtained with $N=1$ for groups $1 \mathrm{D}$ and $1 \mathrm{U}$, maximum deviations are of about $1-2$ per cent the average value $T_{\text {opt }}^{\text {avg }}=$ $\frac{1}{N} \sum_{i=1}^{N} T_{o p t}^{i}$ for each cable.

Average axial cable values are collected in Table 5, together with the maximum deviation from the average axial force in each group of cables. It can be seen that the maximum deviation is negligible (around $2-3$ per cent of the mean value) for the four cables of groups $1 \mathrm{D}, 1 \mathrm{U}$. On the contrary, the cable axial forces in the other groups show maximum deviations up to 16 per cent and 11 per cent, for groups $2 \mathrm{D}$ and $3 \mathrm{U}$, respectively. In spite of these important discrepancies, the global axial force acting on a group of cables aligned on the same transverse cross-section and located upstream and downstream was almost identical, thus confirming the global symmetry of the cable system supporting the bridge deck.

Finally, Table 5 compares the experimental average axial forces $T_{\text {group }}^{\text {opt }}$ on each group of cables with the corresponding FEA mean values $T_{\text {group }, M 02}^{\text {opt }}$ derived from the M02 FE model presented in Section 4.2. For groups $2 \mathrm{U}$ and $2 \mathrm{D}$, it can be seen that the discrepancies between experimental and FEA average values are acceptable, and around 10\%. In case of group 1 (cables close to the National Route n.13) and group 3 (cables on the pylon side), on the contrary, a marked difference was found between the corresponding force values, with discrepancy up to $25 \%$, in absolute value. One motivation of this large inaccuracy may be connected with the absence - in the above presented FE model - of reference to well-defined construction phases for the cablestayed bridge under study, since the self-weights and dead loads were applied directly to the final geometrical configuration of the structure. This confirms the usefulness of dynamic testing on estimating the axial force in cables of stayed-bridges. It should be also noted that additional calculations carried out on the M02 FE model subject to the identified values of the cable axial forces (e.g., average experimental values derived from Table 5), resulted in identical mode ordering and maximum discrepancy on natural frequencies up to $0.02-0.04 \%$ with respect to the values collected in Table 2 .

\subsection{Sensitivity of the bridge to damage in stay cables}

During the Year 2010, two cables belonging to the group $2 \mathrm{U}$ were separately interested by the collapse of the stays-deck connection detail. According to Table 5, the marked difference in identified axial forces on the cables belonging to groups 2 could be considered as symptom of a potential anomaly of the suspension system. Consequently, with the aim of investigating the sensitivity of the natural frequencies, vibration modes and axial forces on the stays with respect to possible damage on the suspending system, an extensive numerical analysis was carried out by using the refined M02 FE model (M02 - FULL, in the following) as reference configuration for the undamaged bridge. Among several simulations, six damage scenarios will be considered in the sequel. They correspond to separately removing one or two cables from the groups $1 \mathrm{U}, 2 \mathrm{U}$ and $3 \mathrm{U}$ of cables. Both the Step I and Step II described in Section 4.2 were carried out for each one of these configurations.

The main results of numerical simulations are collected in Table 6 and Figures 12-16. The labels '1U1 ' and ' $1 \mathrm{U}-2$ ' denote the damage in one or in two cables belonging to the group $1 \mathrm{U}$, respectively. As shown, an appreciable sensitivity of the bridge dynamic response to the induced damage was generally found, hence highlighting the usefulness of diagnostic investigations based on modal data.

In terms of natural frequencies (see Table 6), all the damaged models generally showed small reduction, ranging from $0.5 \%$ to $1 \%$ of the M02-FULL undamaged values. In few cases only, large variations up to $5 \%$ were found. Negligible frequency sensitivity to damage was also generally noticed for higher order modes, e.g., OMA modes 5 and 6 . 
Worth of interest is the effect of damage on the lower vibration modes of the bridge. The bridge manifested an appreciable sensitivity of principal mode 1 to damage (e.g., OMA mode 0 in the notation of Table 2). In particular, Figure 12 shows that progressive removal of a single or two cables in the groups 1 and 3 resulted in increasing mode shape discrepancy with respect to the undamaged configuration. On the contrary, FEA mode 1 subjected to damage in the central group 2 highlighted an apparent misleading modification of the modal shape, where the effect of removing a single cable seems larger than that induced by the removal of two cables, see Figures 12 (scenarios $2 U-1$ and $2 U-2$ ). The reason of this finding is related to the vicinity of the natural frequencies of the two modes, e.g., 1.599 and $1.619 \mathrm{~Hz}$ in the undamaged configuration. A detailed numerical study was carried out to assess the sensitivity of this pair of natural frequencies and related mode shapes. Figure 13 shows the behavior of the natural frequencies of FEA modes 1 and 2 in the $2 U-1$ and $2 U-2$ damage configurations. Natural frequency values are evaluated as functions of the damage ratio $R_{d}=A_{\text {cable }, \text { dam }} / A_{\text {cable }}$, where $A_{\text {cable,dam }}$ and $A_{\text {cable }}$ denote the cross-section area of the damaged and undamaged state, respectively. It can be seen that the increasing of the damage leads to a resonant frequency with multiplicity two. As a consequence, the two corresponding vibration modes, whose spatial shapes are of well-defined character before and after the intersection point, mix each other giving rise to a sort of mode hybridization.

Besides this case, appreciable modifications were also found in the mode shape of OMA modes 1, 3 and 4 . Some comparisons are proposed in Figures 14, 15, where the modal amplitudes obtained from the M02 damaged FE model are compared with the corresponding reference $M 02-F U L L$ estimations. It turns out that damage in one or two cables - for the majority of the case studied - generally coincides with a loss of symmetry of the mode shape with respect to the transverse axis of the deck (see, for example, OMA mode 3 in Figure 15).

Finally, the effect of damage on the axial forces in the cables was investigated. Some comparative results are collected in Figure 16, where the maximum variation of axial force on each group of cables, with respect to the average value for the group of stays in the undamaged state, are proposed for the examined damage scenarios. As shown, the removal of one or two cables in a given group of stays generally resulted in marked modification of axial force values on the same group, but variable force modifications on the other upstream groups of stays (depending on the position of localized damage) and almost negligible variations (in the order of $2-5 \%$ ) for the cables on the downstream side of the deck. Largest sensitivity to damage among all the upstream groups was found, in particular, in the group $2 \mathrm{U}$, as demonstrated by almost comparable increase of axial forces on the $2 \mathrm{U}$ group ( $15 \%$ and $32 \%$ for the scenarios $2 U-1$ and $2 U-2$, respectively) and also in the adjacent $1 U$ and $3 U$ groups. The application of damage on the $3 U$ group, conversely, highlighted a predominant variation of axial forces on the same $3 U$ group only. In this case, moderate variations of axial force were in fact noticed for all the other upstream cable groups, while almost negligible effects were again found on the downstream side. Axial force variations and sensitivity to the position of possible localized damage in the suspending system, in conclusion, could certainly represent useful symptoms for diagnostic interpretations. This is particularly evident for those cases (see, for example, Table 6 and Figure 14, configurations $3 U-1$ and $3 U-2$ ) in which the variation of mode shapes and corresponding natural frequencies does not reflect any marked damage, compared to the changes of axial forces on the cables, hence suggesting a diagnostic analysis based on multiple aspects.

\section{Conclusions}

A dynamical characterization of a cable-stayed bridge based on ambient vibration testing and operational modal analysis has been presented in this paper. The correlation between experimental data and numerical predictions was carried out by means of finite element models of increasingly accuracy. A manual tuning procedure was adopted for the development of an appropriate numerical model of the bridge. The mechanical interaction between some components and description of boundary conditions turned out to be relatively complex. A detailed representation of these structural details was achieved by providing a sufficiently refined mesh and a realistic modelling of the constraints at the longitudinal deck girder ends and at the bottom basis of the pylons of the bridge tower. Moreover, a refined description of the connection between cables and tower, and cables and deck was required to obtain an accurate prediction of the dynamic response of the structure.

Estimation of the axial force acting on the steel cables has been also developed, based on local dynamic experiments carried out on the bridge stays and a variational - type identification procedure. The interpretation of the results highlighted an almost uniform distribution of axial forces in symmetrical group of cables, but, at the same time, pointed out significant discrepancies between the axial forces of cables belonging to a 
same group, thus suggesting the presence of potential anomalies and the need of further investigations.

Acknowledgements The authors would like to commemorate the dear friend and colleague Prof. Francesco Benedettini (University of L'Aquila), a great scholar of Structural Dynamics and, specifically, of ambient vibration testing and operational modal analysis methods on bridges. This research was made possible thanks to the interest and the support of the Dipartimento della Protezione Civile of the Friuli Venezia Giulia. The authors would like to gratefully acknowledge the cooperation of Drs. G. Berlasso and C. Garlatti. The collaboration of Prof. Rocco Alaggio and Dr. Daniele Zulli (University of L'Aquila) during dynamic testing is gratefully appreciated.

\section{References}

1. ABAQUS Version 9.12 computer software (2015) Dassault Systemes, Simulia

2. Abdel-Ghaffar AM, Housner GW (1978) Ambient vibration tests of suspension bridge. J Eng Mech Div ASCE 104(5):983-999

3. Allemang RJ, Brown DL (1983) Correlation coefficient for modal vector analysis. Proc 1st Int Modal Analysis Conf IMAC-I, Orlando, Florida 110-116

4. Benedettini F, Gentile C (2011) Operational modal testing and FE model tuning of a cable-stayed bridge. Eng Struct 33:2063-2073

5. Brincker R, Zhang L, Andersen P (2001) Modal identification of output-only systems using frequency domain decomposition. Smart Mater Struct 10:441-445

6. Brownjohn JMW, Dumanoglu AA, Severn RT (1992) Ambient vibration survey of the Faith Sultan Mehmet (second Bosporus) suspension bridge. Earthquake Eng Struct Dyn 21:907-9-24

7. Daniell WE, Macdonald JHG (2007) Improved finite element modelling of a cable-stayed bridge through systematic manual tuning. Eng Struct 29:358-371

8. Felber A, Ventura CE (1995) Port Mann bridge modal testing and model correlation; Part I: experimental testing and modal analysis. Proc 13th Int Modal Analysis Conf IMAC-XIII, Nashville, Tennesse 1150-1156

9. Gentile C, Martinez y Cabrera F (1997) Dynamic investigation of a repaired cable-stayed bridge. Earthquake Eng Struct Dyn 26(1):41-59

10. Gentile C (2010) Deflection measurement on vibrating stay cables by non-contact microwave interferometer. NDT \& E International 43(3):231-240

11. Magalhes F, Cunha A, Caetano E (2008) Dynamic monitoring of a long span arch bridge. Eng Struct 30(10):30343044

12. Mc Lamore VR, Hart G, Stubbs IR (1971) Ambient vibration of two suspension bridges. J Struct Div ASCE 97(10):2567-2582

13. SAP2000 Version 9.1.5 computer software (2000) Computer and Structures, Berkeley, California

14. SVS, ARTeMIS Extractor, Release 3.5 (2005) Structural Vibration Solutions, Aalborg, Denmark

15. van Overschee P, De Moor B (1996) Subspace identification for linear systems: theory, implementation, applications. Boston (London, Dordrecht): Kluwer

16. Welch PD (1967) The use of Fast Fourier Transform for the estimation of power spectra: a method based on time averaging over short, modified periodograms. IEEE Trans Audio Electroacoust 15(2):70-73

17. Wilson JC, Liu T (1991) Ambient vibration measurements on a cable-stayed bridge. Earthquake Eng Struct Dyn 20:723-747 
Table Captions

Table 1. Comparison between experimental (OMA) and analytical results (FEA, M01-A preliminary model). $\mathrm{B}=$ bending, $\mathrm{T}=$ torsional. Mean value of the $r$ th natural frequency $\left(f_{r}\right)$ and damping ratio $\left(\xi_{r}\right)$, with their maximum deviation. $\Delta=100 \times\left(f_{\mathrm{OMA}}-f_{\mathrm{FEA}}\right) / f_{\mathrm{OMA}}$.

Table 2. Comparison between experimental (OMA) and analytical results (FEA). Mean value of the $r$ th natural frequency $\left(f_{r}\right)$ and damping ratio $\left(\xi_{r}\right)$, with their maximum deviation. $\Delta=100 \times\left(f_{\mathrm{OMA}}-f_{\mathrm{FEA}}\right) / f_{\mathrm{OMA}}$.

Table 3. Average natural frequency values measured for each group of cables. $U=$ upstream; $D=$ downstream.

Table 4. Dynamic estimation of axial force values $T_{o p t}^{N}$, in $k N$, on each cable. $\mathrm{U}=$ upstream; $\mathrm{D}=$ downstream. $N=1, \ldots, 6$ is the number of first frequencies considered in equation (11).

Table 5. Dynamic estimation of average axial force values on the cables $T_{\text {opt }}^{a v g}$ and on of each group of cables $T_{\text {group }}^{\text {avg }}$, and their correlation with FE calculations

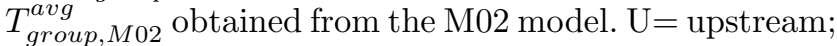
$\mathrm{D}=$ downstream. $T_{\text {total }}=$ total axial force on the cables. $\Delta=100 \times\left(T_{\text {opt }}^{a v g}-T_{\text {group }}^{\text {avg }}\right) / T_{\text {group }}^{\text {avg }}$.

Table 6. Vibration modes of the Pietratagliata bridge with damage in the cables (ABAQUS/Standard). $r=$ mode order; $f=$ natural frequency; $\Delta=100 \times\left(f_{M 02-D A M}-\right.$ $\left.f_{M 02}\right) / f_{M 02}$. n.e. $=$ not evaluated. 


\section{Figure Captions}

Figure 1. Overview of the Pietratagliata cable-stayed bridge: (a) lateral view; (b) steel tower; (c) plan view and (d) cross-section.

Figure 2. Construction details: (a) steel bracings and support on the RC pier (NR n.13 side); (b) stays-tower connection; (c) stays-deck connection; (d) stays-RC foundation connection.

Figure 3. Preliminary FE model M01-A: (a) general view; (b) detail of steel girders and bracing system; (c) first 12 analytical vibration modes $(\mathrm{B}=$ bending; $\mathrm{T}=$ torsional; $\mathrm{P}=$ pylon).

Figure 4. Dynamic testing of the Pietratagliata bridge. Instrumental setups (a) S01 and (b) S02.

Figure 5. (a) EFDD: Example of singular value curves of the spectral density matrix and identification of natural frequencies; (b) SSI: Stabilization diagram (setup S02).

Figure 6. Correlation between OMA (dashed line) and FEA (M01-A preliminary model) normalized vibration modes.

Figure 7. Refined FE-model (M02, ABAQUS/Standard).

Figure 8. Refined FE-model (M02, ABAQUS/Standard). (a) Improper (left) and optimal (right) description of the stays-tower connection; (b) stays-deck connection.

Figure 9. Refined FE-model (M02, ABAQUS/Standard). Detail of the (a) tower base restraint and (b) deck end restraint (Pietratagliata side).

Figure 10. Refined FE model M02 (ABAQUS/Standard). First vibration mode at $1.599 \mathrm{~Hz}$.

Figure 11. Singular value curves of the spectral density matrix evaluated from the (a) half-sum and (b) halfdifference of the experimental responses.

Figure 12. Effects of damage in the cables on the vibration modes of the bridge. OMA mode 0. Row (a): upstream side; row (b): downstream side (ABAQUS/Standard, Model M02-Full). Left (position 0 m): National Route n.13 side; right (position $67 \mathrm{~m}$ ): Pietratagliata side.

Figure 13. Effects of damage in the cables on the vibration modes of the bridge. FEA natural frequencies corresponding to OMA modes 0 and 1 , as a function of the damage ratio $R_{d}=A_{\text {cable,dam }} / A_{\text {cable }}$, for the configurations 2U-1 (left) and 2U-2 (right) (ABAQUS/Standard).

Figure 14. Effects of damage in the cables on the normalized vibration modes of the bridge. OMA mode 1. Row (a): upstream side; row (b): downstream side (ABAQUS/Standard, Model M02-Full). Left (position $0 \mathrm{~m}$ ): National Route n.13 side; right (position $67 \mathrm{~m}$ ): Pietratagliata side.

Figure 15. Effects of damage in the cables on the normalized vibration modes of the bridge. OMA mode 3. Row (a): upstream side; row (b): downstream side (ABAQUS/Standard, Model M02-Full). Left (position $0 \mathrm{~m}$ ): National Route $\mathrm{n} .13$ side; right (position $67 \mathrm{~m}$ ): Pietratagliata side.

Figure 16. Effects of damage in the cables on the average axial forces $T$ on each group of stays (ABAQUS/Standard). $\Delta=100 \times\left(T_{M 02-D A M}-T_{M 02}\right) / T_{M 02}$. 
1

Table 1 Comparison between experimental (OMA) and analytical results (FEA, M01-A preliminary model). B= bending, $\mathrm{T}=$ torsional. Mean value of the $r$ th natural frequency $\left(f_{r}\right)$ and damping ratio $\left(\xi_{r}\right)$, with their maximum deviation. $\Delta=$ $100 \times\left(f_{\mathrm{OMA}}-f_{\mathrm{FEA}}\right) / f_{\mathrm{OMA}}$.

\begin{tabular}{llllllll}
\hline OMA & & & FEA & \\
Order & Mode type & $f_{r}$ & $\xi_{r}$ & Order & $f_{r}$ & $\Delta$ & $M A C$ \\
$r$ & - & {$[\mathrm{Hz}]$} & {$[\%]$} & $r$ & {$[\mathrm{~Hz}]$} & {$[\%]$} & {$[\%]$} \\
\hline 1 & 1st B & $1.665 \pm 0.001$ & $1.2 \pm 0.5$ & 1 & 1.452 & 12.8 & 99.6 \\
2 & 1st T & $2.669 \pm 0.014$ & $0.6 \pm 0.1$ & 2 & 2.243 & 16.0 & 89.3 \\
3 & 2nd B & $3.411 \pm 0.012$ & $0.7 \pm 0.2$ & 3 & 2.958 & 13.3 & 97.3 \\
4 & 2nd T & $4.750 \pm 0.007$ & $0.4 \pm 0.0$ & 7 & 5.160 & -8.6 & 97.3 \\
5 & 3rd B & $5.261 \pm 0.009$ & $0.7 \pm 0.2$ & 6 & 4.561 & 13.3 & 93.4 \\
6 & 3rd T & $7.336 \pm 0.002$ & $0.9 \pm 0.2$ & 9 & 7.483 & -2.0 & 91.7 \\
\hline
\end{tabular}


1

2 3 4 5 6 7 8 9 10

Table 2 Comparison between experimental (OMA) and analytical results (FEA). Mean value of the $r$ th natural frequency $\left(f_{r}\right)$ and damping ratio $\left(\xi_{r}\right)$, with their maximum deviation. $\Delta=100 \times\left(f_{\mathrm{OMA}}-f_{\mathrm{FEA}}\right) / f_{\mathrm{OMA}}$.

\begin{tabular}{llllllllll}
\hline OMA & \multicolumn{3}{c}{ FEA (M01-B) } & \multicolumn{5}{c}{ FEA (M02) } \\
Order & $f_{r}$ & Order & $f_{r}$ & $\Delta$ & $M A C$ & Order & $f_{r}$ & $\Delta$ & $M A C$ \\
$r$ & {$[\mathrm{~Hz}]$} & $r$ & {$[\mathrm{~Hz}]$} & {$[\%]$} & {$[\%]$} & $r$ & {$[\mathrm{~Hz}]$} & {$[\%]$} & {$[\%]$} \\
\hline 0 & 1.619 & - & - & - & - & 1 & 1.599 & 1.2 & 98.5 \\
1 & 1.665 & 1 & 1.564 & 6.1 & 98.4 & 2 & 1.619 & 2.8 & 99.5 \\
2 & 2.669 & 2 & 2.403 & 10.0 & 89.3 & 3 & 2.691 & -0.8 & 97.3 \\
3 & 3.411 & 3 & 3.239 & 5.0 & 94.8 & 5 & 3.234 & 5.2 & 96.0 \\
4 & 4.750 & 5 & 5.106 & -7.5 & 97.8 & 7 & 4.717 & 0.7 & 76.3 \\
5 & 5.261 & 6 & 5.414 & -2.9 & 93.8 & 8 & 5.295 & -0.6 & 48.4 \\
6 & 7.336 & 11 & 8.490 & -15.7 & 93.8 & 13 & 7.371 & -0.5 & 78.4 \\
\hline
\end{tabular}


1

2 3 4 5 6 7 8 9 10 11 12 13 14 15 16 17 18 19 20 21 22 23 24 25 26 27 28 29 30 31 32 33 34 35 36 37 38 39 40 41 42 43 44 45 46 47 48 49 50 51 52 53 54 55 56 57 58 59 60 61 62 63 64 65

\begin{tabular}{lllllll}
\hline $\begin{array}{l}\text { Order } \\
r\end{array}$ & $1 \mathrm{D}$ & $1 \mathrm{U}$ & $2 \mathrm{D}$ & $2 \mathrm{U}$ & $3 \mathrm{D}$ & $3 \mathrm{U}$ \\
\hline 1 & 1.303 & $1 \mathrm{~Hz}]$ & {$[\mathrm{Hz}]$} & {$[\mathrm{Hz}]$} & {$[\mathrm{Hz}]$} & {$[\mathrm{Hz}]$} \\
2 & 2.460 & 2.490 & 2.143 & 2.167 & 3.314 & 3.260 \\
3 & 3.717 & 3.772 & 6.549 & 4.294 & 6.653 & 6.738 \\
4 & 5.057 & 5.249 & 8.688 & 8.811 & 10.413 & 10.279 \\
5 & 6.302 & 6.387 & 10.986 & 11.112 & 18.762 & 14.172 \\
6 & 7.660 & 7.752 & 13.474 & 13.803 & 23.621 & 23.358 \\
\hline
\end{tabular}


1

2 3 4 5 6 7 8 9 10

Table 4 Dynamic estimation of axial force values $T_{o p t}^{N}$, in $k N$, on each cable. $\mathrm{U}=$ upstream; $\mathrm{D}=\operatorname{downstream} . N=1, \ldots, 6$ is the number of first frequencies considered in equation (11).

\begin{tabular}{|c|c|c|c|c|c|c|c|}
\hline Group & Cable & $\begin{array}{l}\text { Mode } \\
N\end{array}$ & & & & & \\
\hline & & 1 & 2 & 3 & 4 & 5 & 6 \\
\hline \multirow[t]{4}{*}{$1 \mathrm{D}$} & $C_{1}$ & 416.0 & 388.8 & 381.6 & 380.6 & 378.7 & 377.9 \\
\hline & $C_{2}$ & 393.2 & 30.7 & 370.0 & 370.5 & 368.8 & 368.2 \\
\hline & $C_{3}$ & 393.2 & 370.7 & 364.9 & 364.3 & 362.5 & 361.5 \\
\hline & $C_{4}$ & 423.8 & 392.0 & 382.8 & 381.5 & 378.9 & 377.8 \\
\hline \multirow[t]{4}{*}{$1 \mathrm{U}$} & $C_{1}$ & 385.7 & 377.2 & 376.6 & 379.0 & 378.0 & 377.3 \\
\hline & $C_{2}$ & 393.2 & 374.7 & 370.0 & 370.5 & 369.1 & 368.4 \\
\hline & $C_{3}$ & 423.8 & 396.3 & 389.1 & 388.5 & 386.6 & 385.5 \\
\hline & $C_{4}$ & 423.8 & 398.4 & 392.2 & 392.3 & 390.2 & 389.5 \\
\hline \multirow[t]{4}{*}{$2 \mathrm{D}$} & $C_{1}$ & 598.2 & 594.5 & 602.5 & 603.5 & 602.4 & 605.4 \\
\hline & $C_{2}$ & 617.6 & 612.3 & 620.3 & 619.4 & 618.6 & 622.5 \\
\hline & $C_{3}$ & 464.8 & 454.0 & 458.7 & 457.6 & 457.2 & 460.1 \\
\hline & $C_{4}$ & 505.4 & 497.3 & 503.3 & 502.4 & 501.7 & 504.9 \\
\hline \multirow[t]{4}{*}{$2 \mathrm{U}$} & $C_{1}$ & 529.4 & 524.3 & 530.8 & 530.6 & 529.9 & 531.7 \\
\hline & $C_{2}$ & 517.3 & 510.7 & 516.3 & 515.2 & 514.6 & 518.4 \\
\hline & $C_{3}$ & 511.4 & 501.7 & 506.4 & 505.1 & 504.8 & 507.3 \\
\hline & $C_{4}$ & 572.7 & 564.3 & 568.8 & 567.8 & 567.5 & 563.3 \\
\hline \multirow[t]{4}{*}{$3 \mathrm{D}$} & $C_{1}$ & 463.7 & 474.6 & 476.8 & 481.0 & 485.2 & 488.5 \\
\hline & $C_{2}$ & 430.2 & 442.1 & 445.5 & 447.9 & 451.0 & 455.6 \\
\hline & $C_{3}$ & 463.7 & 469.7 & 469.8 & 472.0 & 477.5 & 481.6 \\
\hline & $C_{4}$ & 404.2 & 411.1 & 413.5 & 414.8 & 417.6 & 422.1 \\
\hline \multirow[t]{4}{*}{$3 \mathrm{U}$} & $C_{1}$ & 417.1 & 434.8 & 433.4 & 435.3 & 439.0 & 442.6 \\
\hline & $C_{2}$ & 463.7 & 459.6 & 466.9 & 473.9 & 477.9 & 483.8 \\
\hline & $C_{3}$ & 423.6 & 422.8 & 425.8 & 430.3 & 434.7 & 438.5 \\
\hline & $C_{4}$ & 519.8 & 485.5 & 498.8 & 508.5 & 515.0 & 521.1 \\
\hline
\end{tabular}


1

Table 5 Dynamic estimation of average axial force values on the cables $T_{\text {opt }}^{a v g}$ and on of each group of cables $T_{g r o u p}^{a v g}$, and their correlation with FE calculations $T_{\text {group }, M 02}^{\text {avg }}$ obtained from the M02 model. U= upstream; $\mathrm{D}=$ downstream. $T_{\text {total }}=$ total axial force on the cables. $\Delta=100 \times\left(T_{\text {opt }}^{a v g}-T_{\text {group }}^{a v g}\right) / T_{\text {group }}^{a v g}$.

\begin{tabular}{|c|c|c|c|c|c|c|c|c|c|c|}
\hline Group & $\begin{array}{l}T_{a v g}^{o p t} \\
{[\mathrm{kN}]}\end{array}$ & & & & $\begin{array}{l}\text { Tovgoup } \\
{[\mathrm{kN}]}\end{array}$ & $\begin{array}{l}\Delta \\
{[\%]}\end{array}$ & & & & $\begin{array}{l}T_{\text {group }}^{\text {avg }}, \mathrm{M02} \\
{[\mathrm{kN}]}\end{array}$ \\
\hline & $C_{1}$ & $C_{2}$ & $C_{3}$ & $C_{4}$ & & $C_{1}$ & $C_{2}$ & $C_{3}$ & $C_{4}$ & \\
\hline 1D & 387.3 & 374.3 & 369.5 & 389.5 & 380.1 & 1.9 & 3.2 & -2.2 & -2.9 & 262.4 \\
\hline $1 \mathrm{U}$ & 379.0 & 374.3 & 395.0 & 397.7 & 386.5 & -1.9 & 1.6 & 2.8 & -2.5 & 263.9 \\
\hline $2 \mathrm{D}$ & 601.1 & 618.5 & 458.7 & 502.5 & 545.2 & -10.3 & -13.4 & 15.9 & 7.8 & 604.3 \\
\hline $2 \mathrm{U}$ & 529.5 & 515.4 & 506.1 & 567.4 & 529.6 & 0.0 & 2.7 & 4.4 & -7.1 & 605.3 \\
\hline $3 \mathrm{D}$ & 478.3 & 445.4 & 472.4 & 413.9 & 452.5 & -5.7 & 1.6 & -4.4 & 8.5 & 524.8 \\
\hline $3 \mathrm{U}$ & 433.7 & 471.0 & 429.3 & 508.2 & 460.6 & 5.8 & -2.3 & 6.8 & -10.3 & 525.1 \\
\hline$T_{\text {total }}$ & & & & & 11142.6 & & & & & 11080.0 \\
\hline
\end{tabular}


1
Table 6 Vibration modes of the Pietratagliata bridge with damage in the cables (ABAQUS/Standard). $r=$ mode order; $f=$ natural frequency; $\Delta=100 \times\left(f_{M 02}-D A M-f_{M 02}\right) / f_{M 02}$. n.e. $=$ not evaluated.

\begin{tabular}{|c|c|c|c|c|c|c|c|c|c|}
\hline OMA Order & & $r$ & 0 & 1 & 2 & 3 & 4 & 5 & 6 \\
\hline \multirow{3}{*}{$M 02-F U L L$} & & $r$ & 1 & 2 & 3 & 5 & 7 & 8 & 13 \\
\hline & & $f_{r}[\mathrm{~Hz}]$ & 1.599 & 1.619 & 2.691 & 3.238 & 4.718 & 5.296 & 7.372 \\
\hline & & $M A C[\%]$ & 98.3 & 99.5 & 97.3 & 96.0 & 76.3 & n.e. & n.e. \\
\hline \multirow[t]{24}{*}{$M 02-D A M$} & $1 U-1$ & $r$ & 1 & 2 & 3 & 4 & 7 & 8 & 13 \\
\hline & & $f_{r}[\mathrm{~Hz}]$ & 1.597 & 1.611 & 2.685 & 3.192 & 4.713 & 5.294 & 7.362 \\
\hline & & $\Delta[\%]$ & -0.11 & -0.47 & -0.23 & -1.41 & -0.09 & -0.04 & -0.13 \\
\hline & & $M A C$ [\%] & 96.4 & 97.7 & 97.9 & 82.5 & 55.7 & n.e. & n.e. \\
\hline & $1 U-2$ & $r$ & 1 & 2 & 3 & 4 & 6 & 8 & 13 \\
\hline & & $f_{r}[\mathrm{~Hz}]$ & 1.591 & 1.604 & 2.675 & 3.174 & 4.666 & 5.292 & 7.357 \\
\hline & & $\Delta[\%]$ & -0.50 & -0.91 & -0.58 & -1.97 & -1.10 & -0.07 & -0.20 \\
\hline & & $M A C[\%]$ & 95.8 & 80.5 & 97.9 & 84.7 & 78.1 & n.e. & n.e. \\
\hline & $2 U-1$ & $r$ & 2 & 1 & 3 & 5 & 7 & 8 & 13 \\
\hline & & $f_{r}[\mathrm{~Hz}]$ & 1.599 & 1.590 & 2.668 & 3.237 & 4.716 & 5.290 & 7.369 \\
\hline & & $\Delta[\%]$ & -0.01 & -1.80 & -0.87 & -0.02 & -0.03 & -0.11 & -0.04 \\
\hline & & $M A C[\%]$ & 96.6 & 96.9 & 97.7 & 95.0 & 85.5 & n.e. & n.e. \\
\hline & $2 U-2$ & $r$ & 2 & 1 & 3 & 5 & 7 & 8 & 13 \\
\hline & & $f_{r}[\mathrm{~Hz}]$ & 1.599 & 1.554 & 2.641 & 3.236 & 4.716 & 5.283 & 7.369 \\
\hline & & $\Delta[\%]$ & -0.01 & -4.05 & -1.88 & -0.04 & -0.04 & -0.25 & -0.04 \\
\hline & & $M A C[\%]$ & 97.8 & 97.9 & 97.5 & 94.9 & 88.6 & n.e. & n.e. \\
\hline & $3 U-1$ & $r$ & 1 & 2 & 3 & 4 & 6 & 8 & 13 \\
\hline & & $f_{r}[\mathrm{~Hz}]$ & 1.599 & 1.614 & 2.676 & 3.133 & 4.617 & 5.293 & 7.356 \\
\hline & & $\Delta[\%]$ & -0.01 & -0.28 & -0.55 & -3.22 & -2.14 & -0.06 & -0.20 \\
\hline & & $M A C$ [\%] & 98.7 & 99.1 & 96.8 & 83.3 & 63.3 & n.e. & n.e. \\
\hline & $3 U-2$ & $r$ & 1 & 2 & 3 & 4 & 6 & 8 & 13 \\
\hline & & $f_{r}[\mathrm{~Hz}]$ & 1.598 & 1.607 & 2.643 & 3.225 & 4.499 & 5.289 & 7.343 \\
\hline & & $\Delta[\%]$ & -0.09 & -0.74 & -1.78 & -0.39 & -4.64 & -0.13 & -0.38 \\
\hline & & $M A C[\%]$ & 26.8 & 99.1 & 96.8 & 83.3 & 63.2 & n.e. & n.e. \\
\hline
\end{tabular}


1

2

3

4

5

6

7

8

9

10

11

12

13

14

15

16

17

18

19

20

21

22

23

24

25

26

27

28

29

30

31

32

33

34

35

36

37

38

39

40

41

42

43

44

45

46

47

48

49

50

51

52

53

54

55

56

57

58

59

60

61

62

63

64

65 (a)

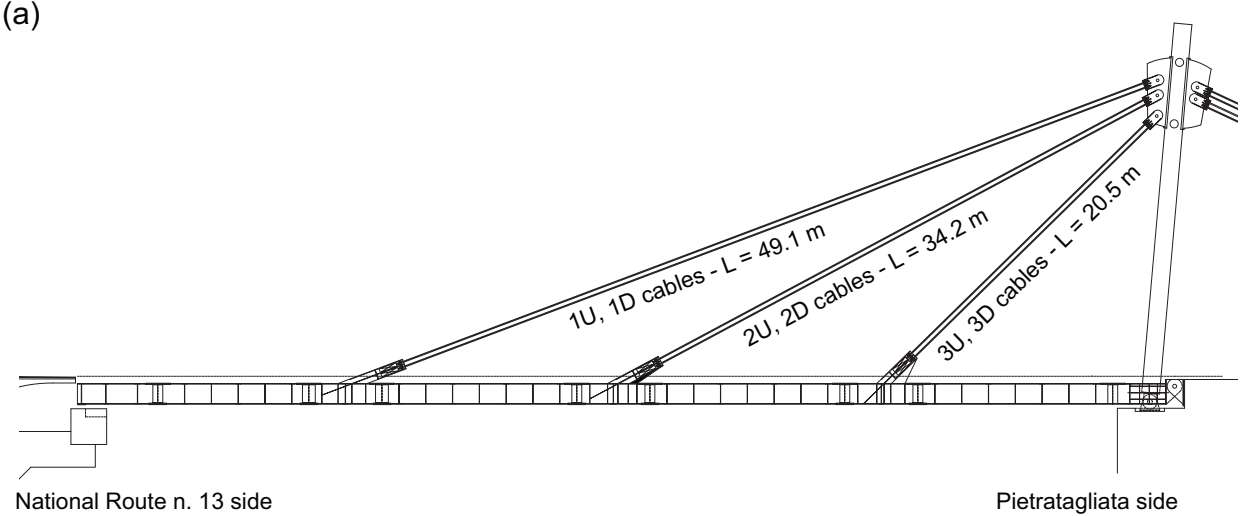

National Route n. 13 side

(c)
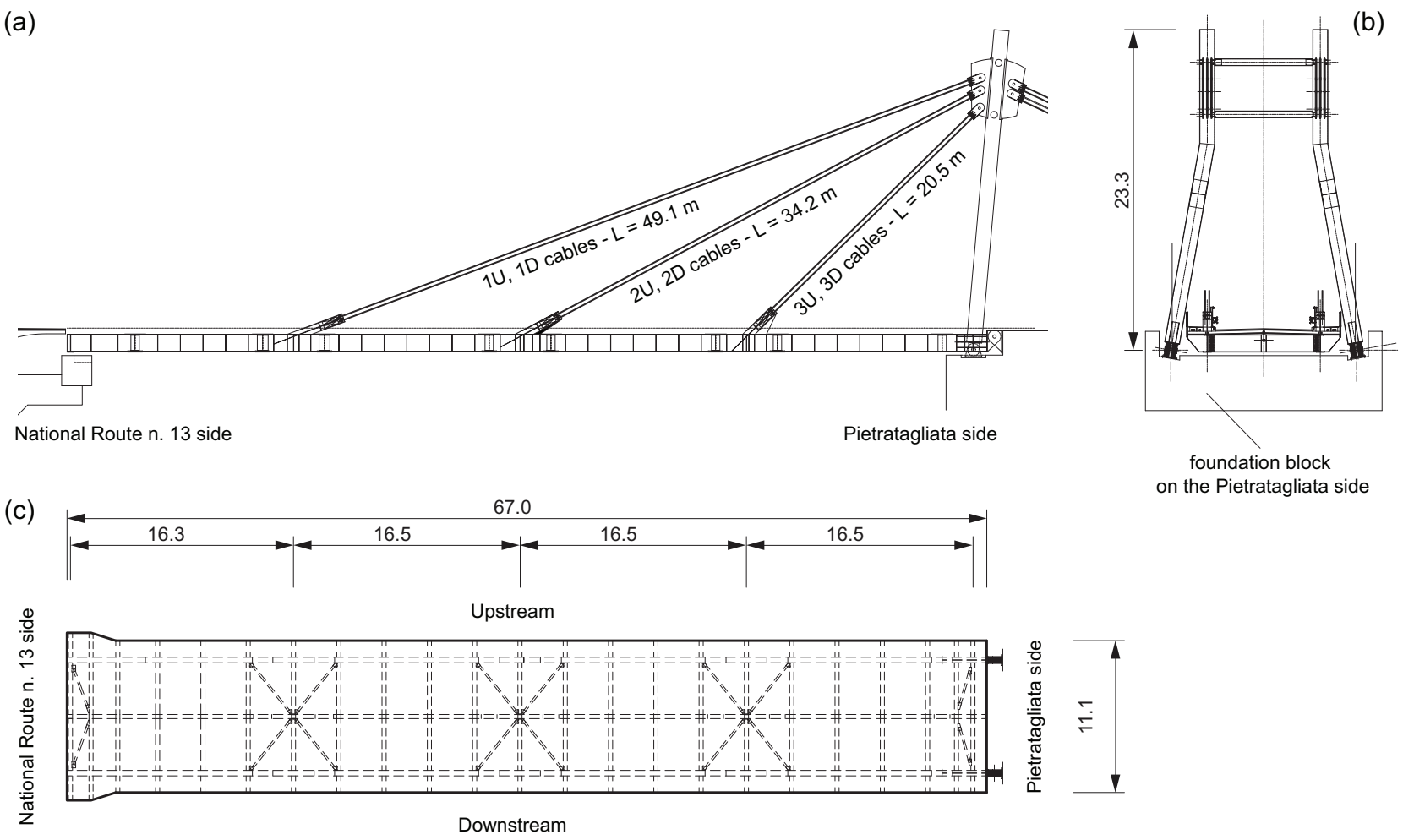

(d)

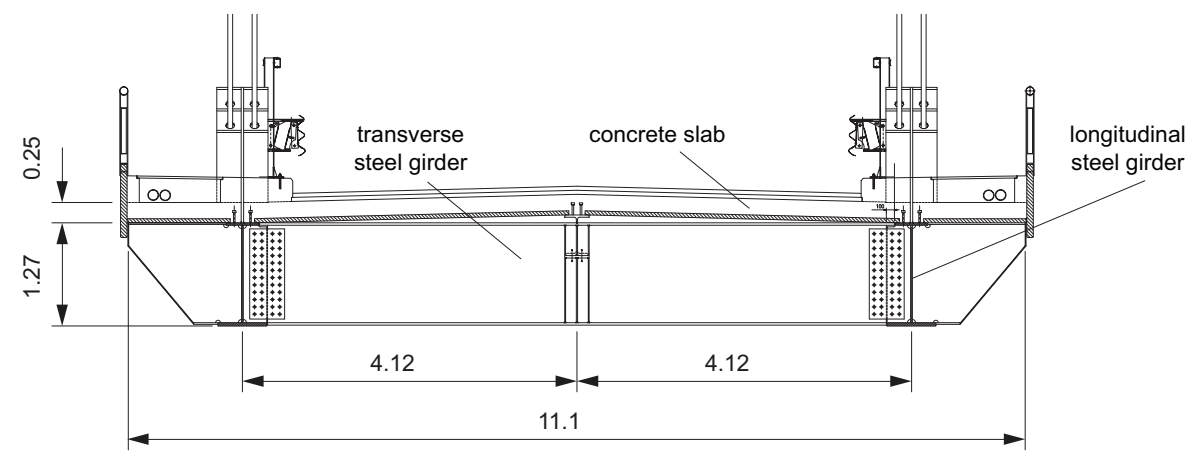

Fig. 1 Overview of the Pietratagliata cable-stayed bridge: (a) lateral view; (b) steel tower; (c) plan view and (d) cross-section. 


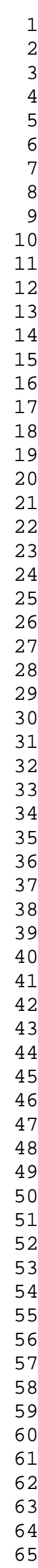

(a)

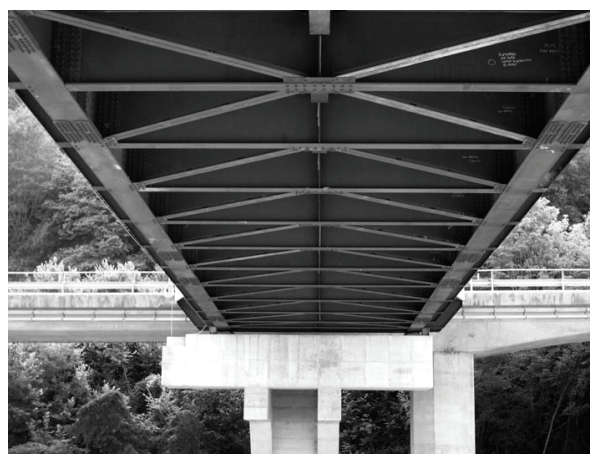

(b)

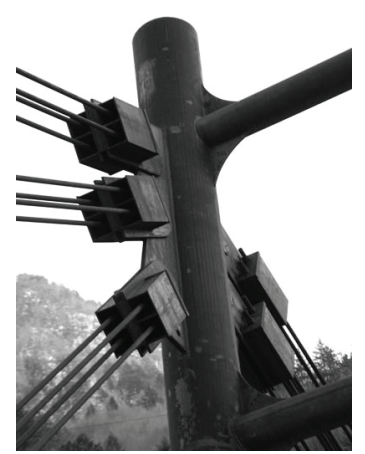

(c)

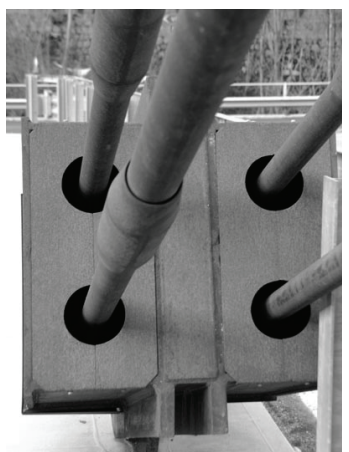

(d)

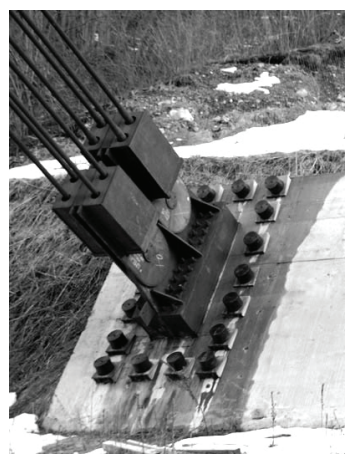

Fig. 2 Construction details: (a) steel bracings and support on the RC pier (NR n.13 side); (b) stays-tower connection; (c) stays-deck connection; (d) stays-RC foundation connection. 
1

2

3

4

5

6

7

8

9

10

11

12

13

14

15

16

17

18

19

20

21

22

23

24

25

26

27

28

29

30

31

32

33

34

35

36

37

38

39

40

41

42

43

44

45

46

47

48

49

50

51

52

53

54

55

56

57

58

59

60

61

62

63

64

65 (a)

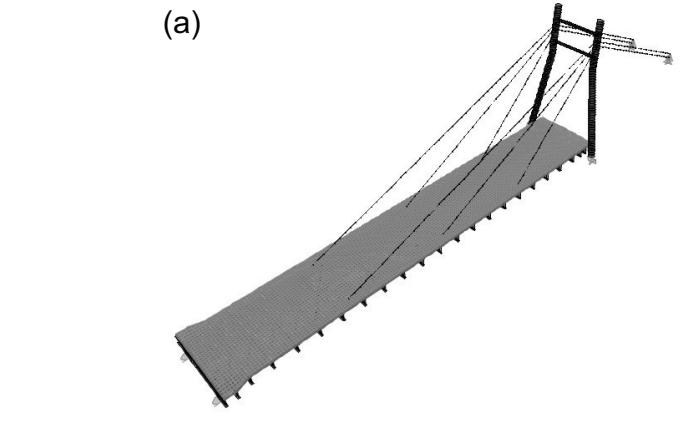

(b)

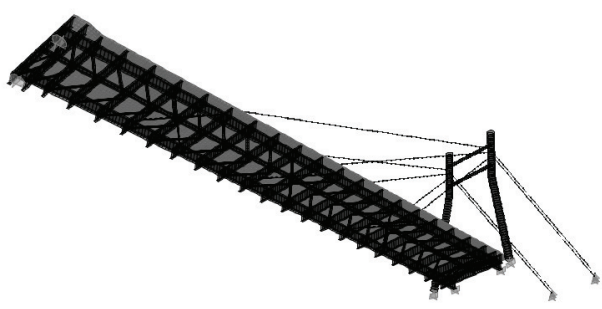

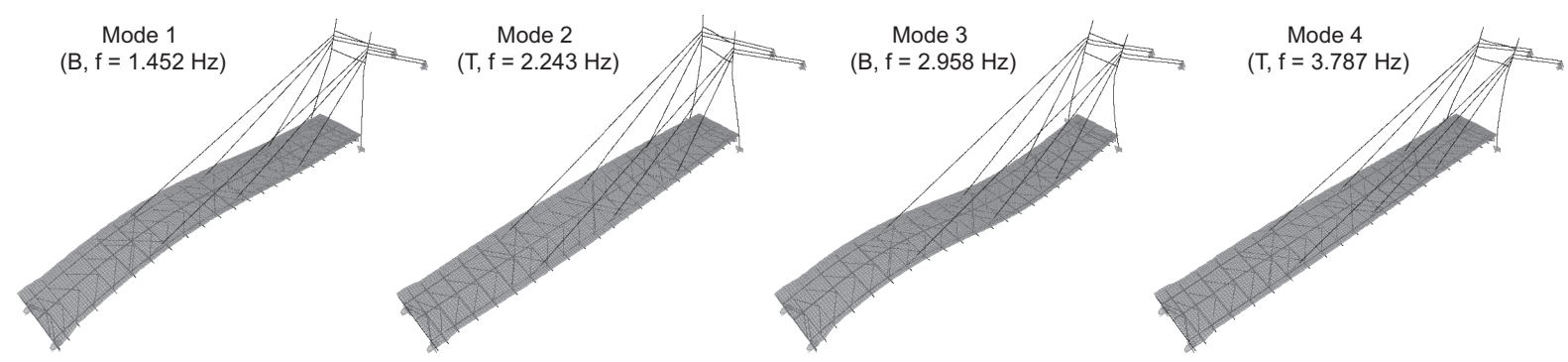
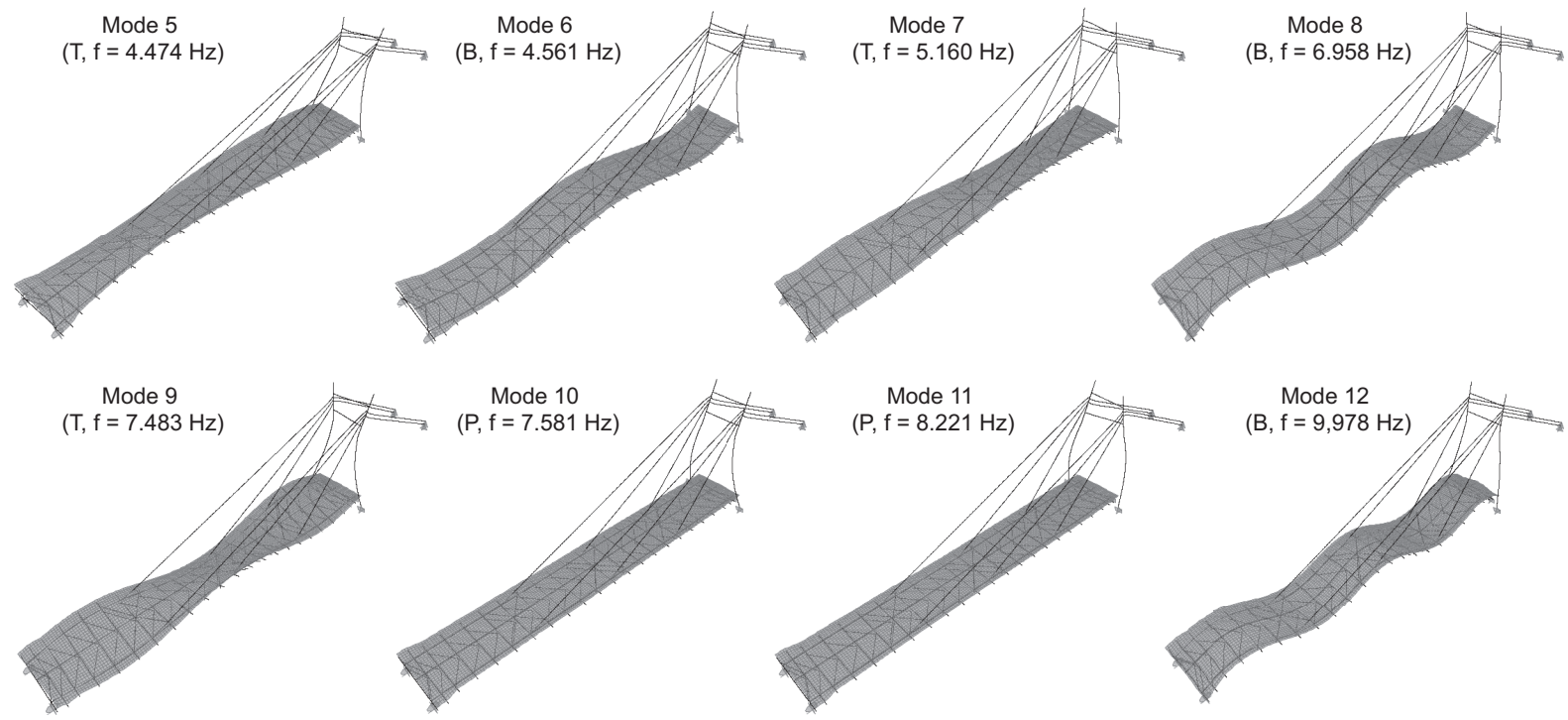

Mode 12

(B, $f=9,978 \mathrm{~Hz}$ )

(c)

Fig. 3 Preliminary FE model M01-A: (a) general view; (b) detail of steel girders and bracing system; (c) first 12 analytical vibration modes $(\mathrm{B}=$ bending; $\mathrm{T}=$ torsional; $\mathrm{P}=$ pylon $)$. 
1

2

3

4

5

6

7

8

10

11

12

13

14

15

16

17

18

19

20

21

22

23

24

25

26

27

28

29

30

31

32

33

34

35

36

37

38

39

40

41

42

43

44

45

46

47

48

49

50

51

52

53

54

55

56

57

58

59

60

61

62

63

64

65

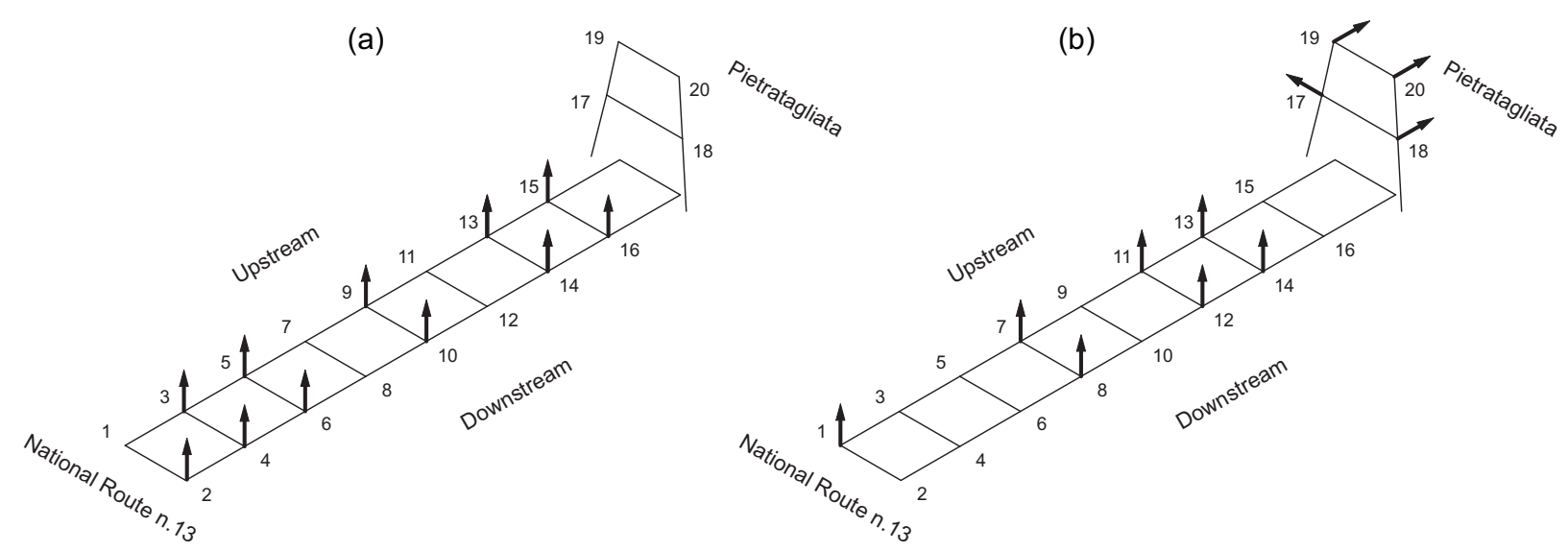

Fig. 4 Dynamic testing of the Pietratagliata bridge. Instrumental setups (a) S01 and (b) S02. 
1

2

3

4

5

6

7

8

9

10

11

12

13

14

15

16

17

18

19

20

21

22

23

24

25

26

27

28

29

30

31

32

33

34

35

36

37

38

39

40

41

42

43

44

45

46

47

48

49

50

51

52

53

54

55

56

57

58

59

60

61

62

63

64

65 (a)

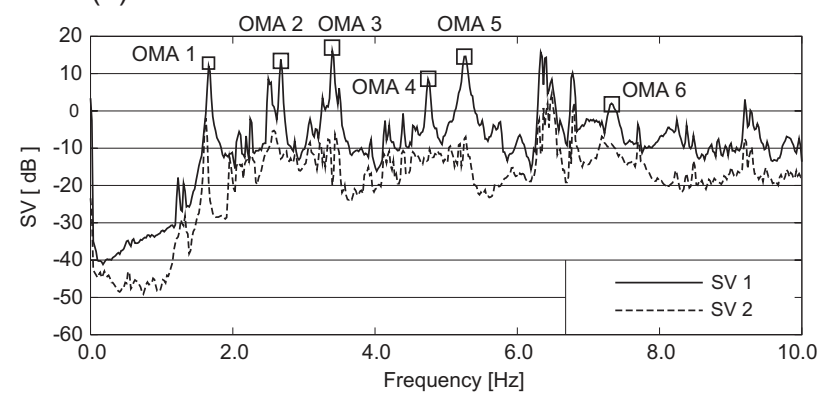

(b)

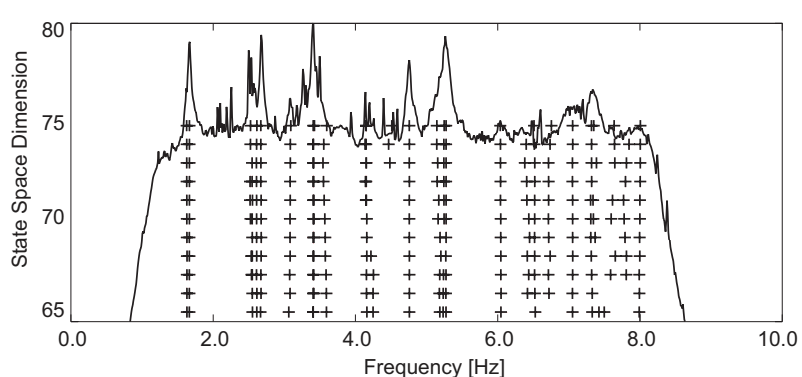

Fig. 5 (a) EFDD: Example of singular value curves of the spectral density matrix and identification of natural frequencies; (b) SSI: Stabilization diagram (setup S02). 
1

2

3

4

5

6

7

8

9

10

11

12

13

14

15

16

17

18

19

20

21

22

23

24

25

26

27

28

29

30

31

32

33

34

35

36

37

38

39

40

41

42

43

44

45

46

47

48

49

50

51

52

53

54

55

56

57

58

59

60

61

62

63

64

65

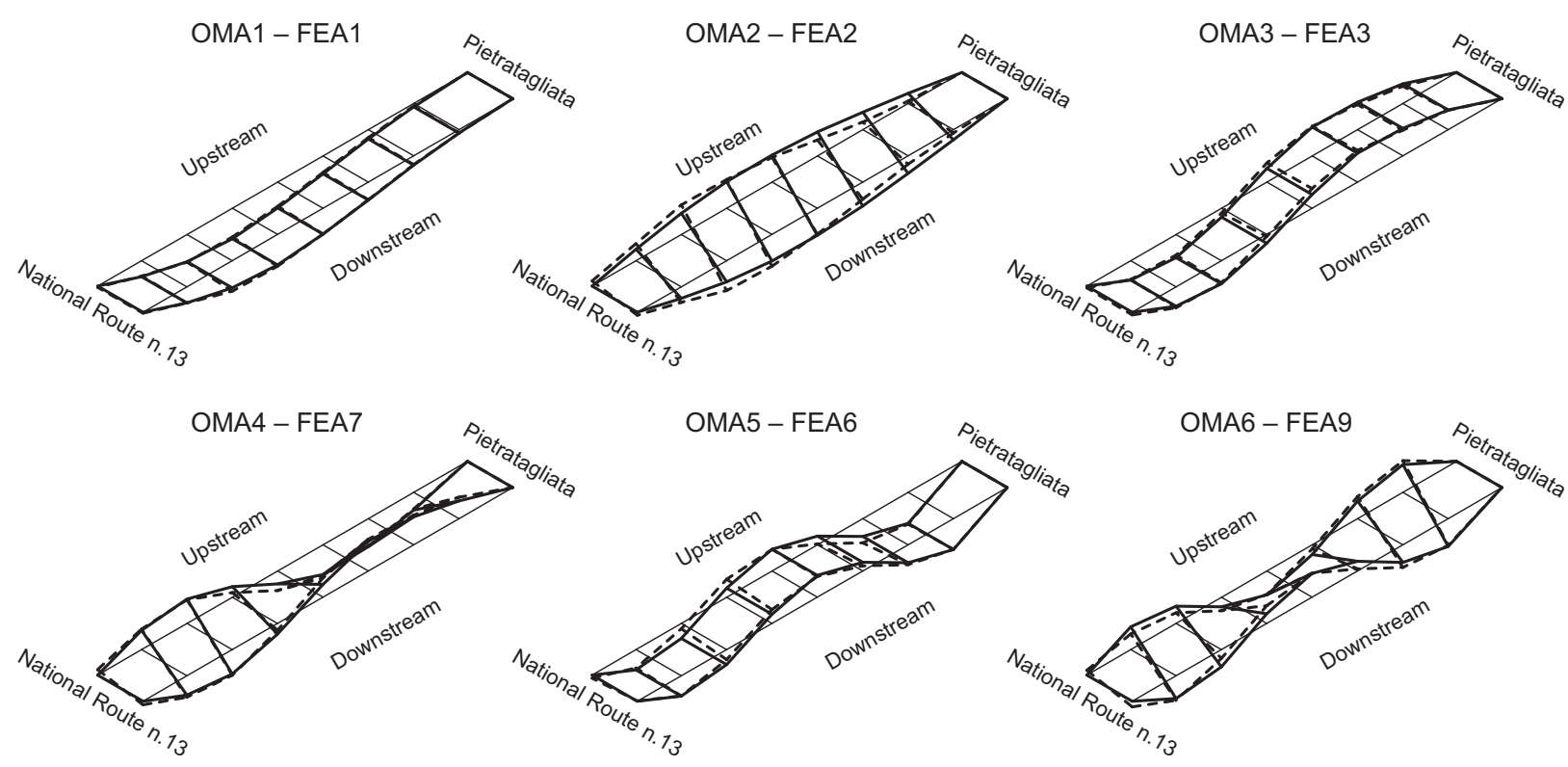

Fig. 6 Correlation between OMA (dashed line) and FEA (M01-A preliminary model) normalized vibration modes. 
1

2

3

4

5

6

7

8

9

10

11

12

13

14

15

16

17

18

19

20

21

22

23

24

25

26

27

28

29

30

31

32

33

34

35

36

37

38

39

40

41

42

43

44

45

46

47

48

49

50

51

52

53

54

55

56

57

58

59

60

61

62

63

64

65
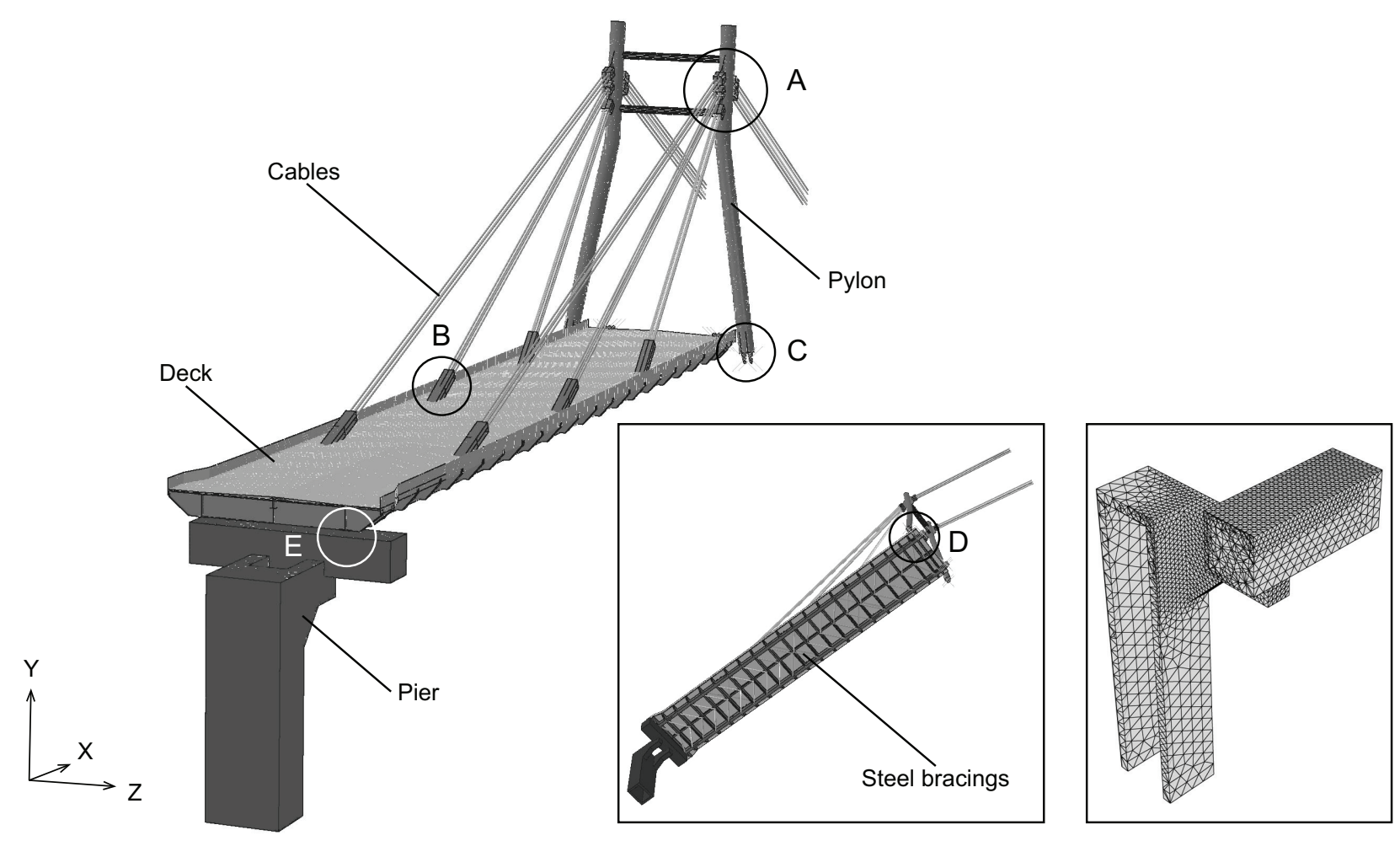

Fig. 7 Refined FE-model (M02, ABAQUS/Standard). 

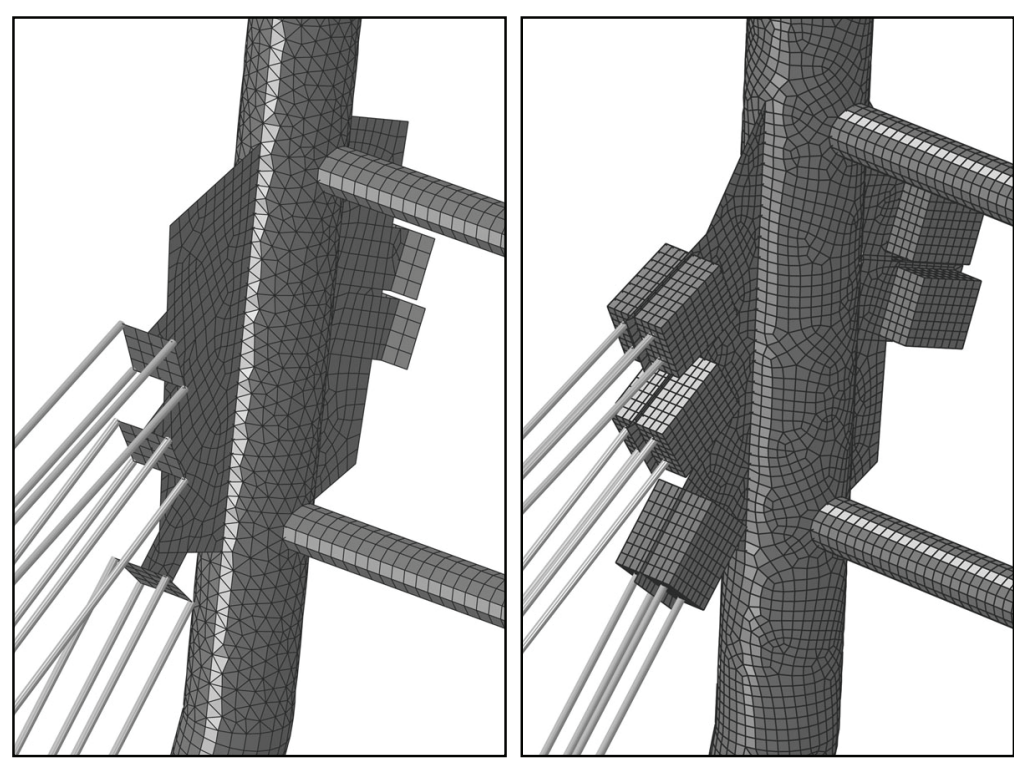

(a)

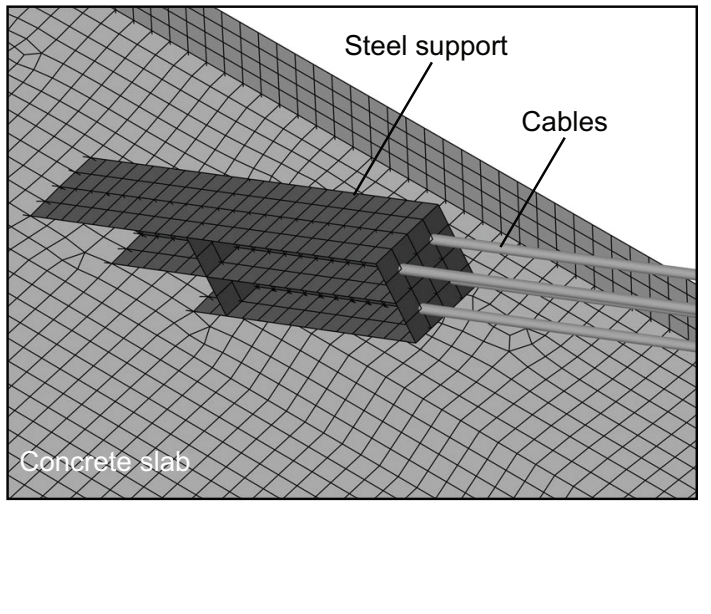

(b)

Fig. 8 Refined FE-model (M02, ABAQUS/Standard). (a) Improper (left) and optimal (right) description of the stays-tower connection; (b) stays-deck connection. 
1

2

3

4

5

6

7

8

9

10

11

12

13

14

15

16

17

18

19

20

21

22

23

24

25

26

27

28

29

30

31

32

33

34

35

36

37

38

39

40

41

42

43

44

45

46

47

48

49

50

51

52

53

54

55

56

57

58

59

60

61

62

63

64

65 (a)

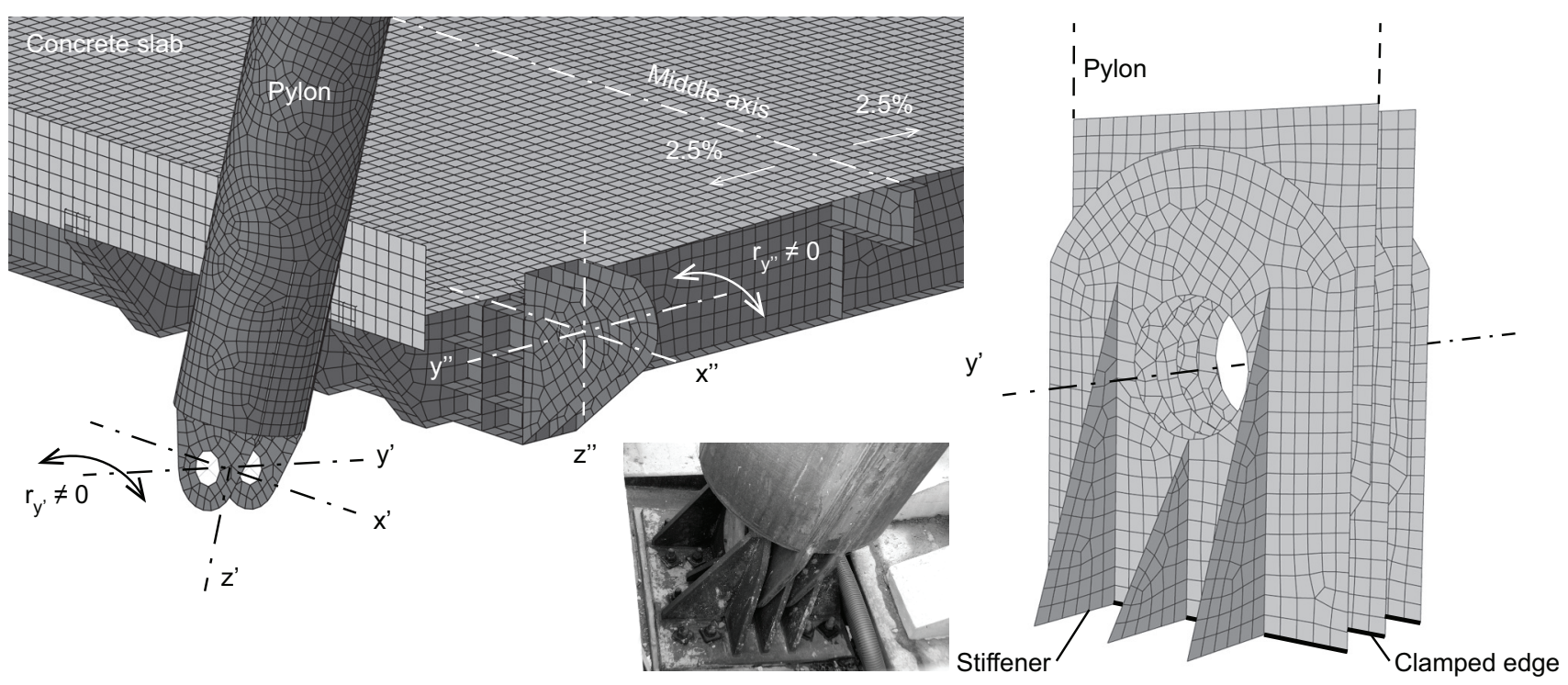

Fig. 9 Refined FE-model (M02, ABAQUS/Standard). Detail of the (a) tower base restraint and (b) deck end restraint (Pietratagliata side).

(b) 
1

2

3

4

5

6

7

9

10

11

12

13

14

15

16

17

18

19

20

21

22

23

24

25

26

27

28

29

30

31

32

33

34

35

36

37

38

39

40

41

42

43

44

45

46

47

48

49

50

51

52

53

54

55

56

57

58

59

60

61

62

63

64

65

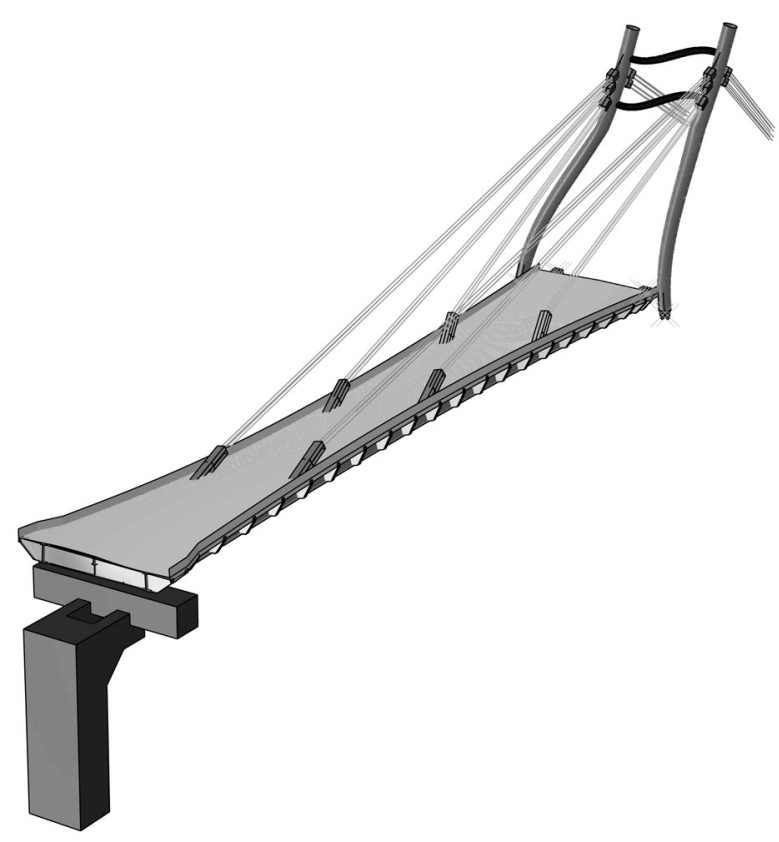

Fig. 10 Refined FE model M02 (ABAQUS/Standard). First vibration mode at $1.599 \mathrm{~Hz}$. 
1

2

3

4

5

6

7

8

9

10

11

12

13

14

15

16

17

18

19

20

21

22

23

24

25

26

27

28

29

30

31

32

33

34

35

36

37

38

39

40

41

42

43

44

45

46

47

48

49

50

51

52

53

54

55

56

57

58

59

60

61

62

63

64

65 (a)

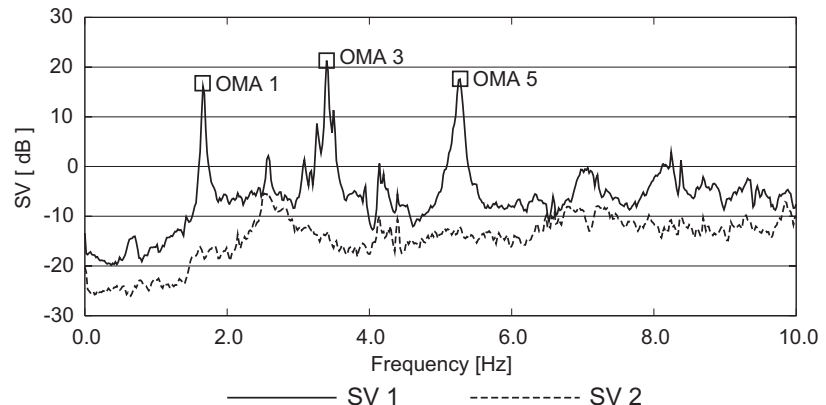

(b)

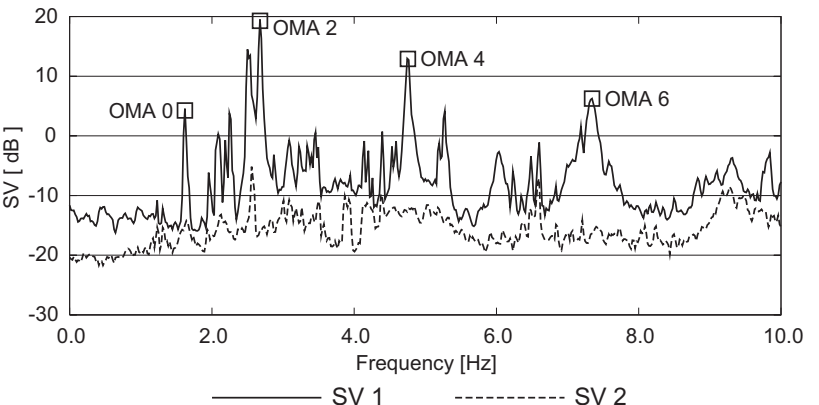

Fig. 11 Singular value curves of the spectral density matrix evaluated from the (a) half-sum and (b) half-difference of the experimental responses. 
1
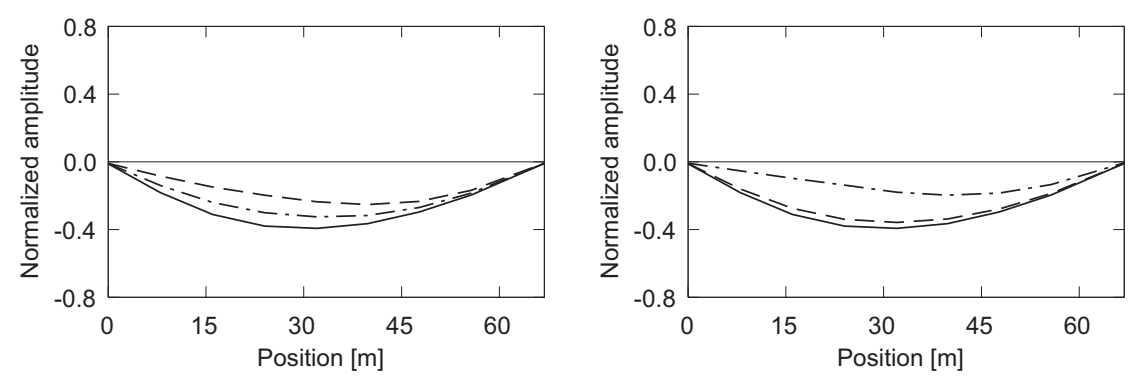

(b)
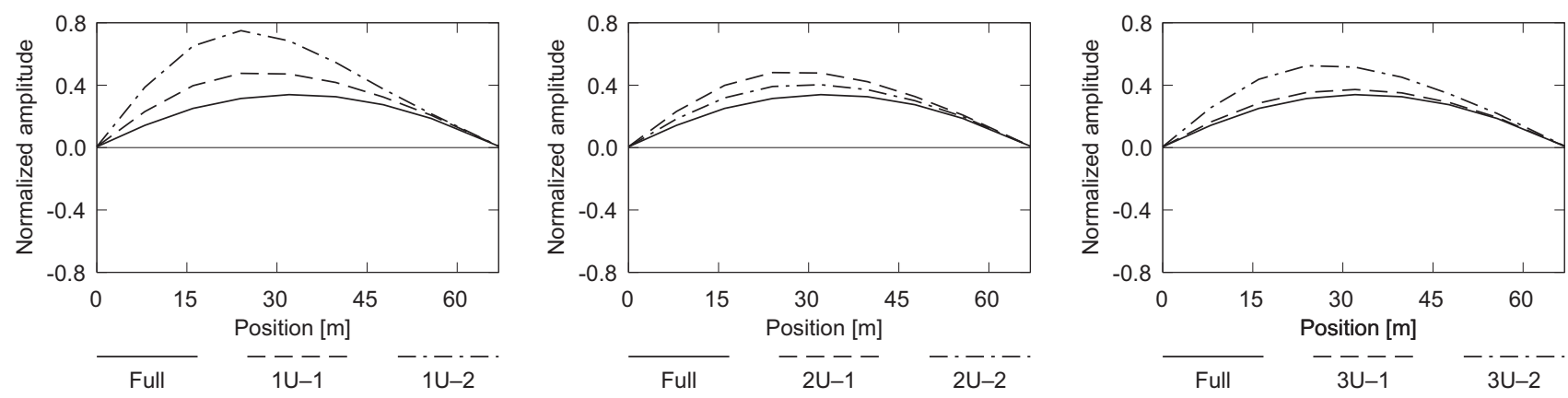

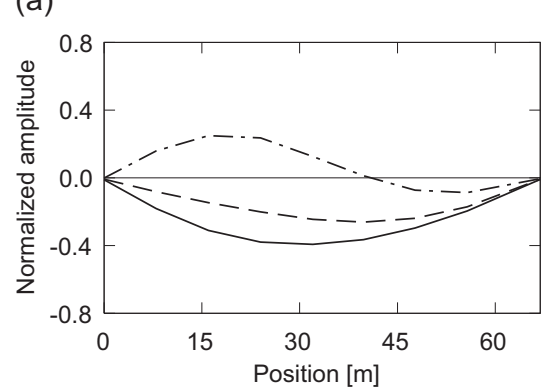

Fig. 12 Effects of damage in the cables on the vibration modes of the bridge. OMA mode 0. Row (a): upstream side; row (b): downstream side (ABAQUS/Standard, Model M02-Full). Left (position 0 m): National Route n.13 side; right (position $67 \mathrm{~m})$ : Pietratagliata side. 
1

2

3

4

5

6

7

8

9

10

11

12

13

14

15

16

17

18

19

20

21

22

23

24

25

26

27

28

29

30

31

32

33

34

35

36

37

38

39

40

41

42

43

44

45

46

47

48

49

50

51

52

53

54

55

56

57

58

59

60

61

62

63

64

65
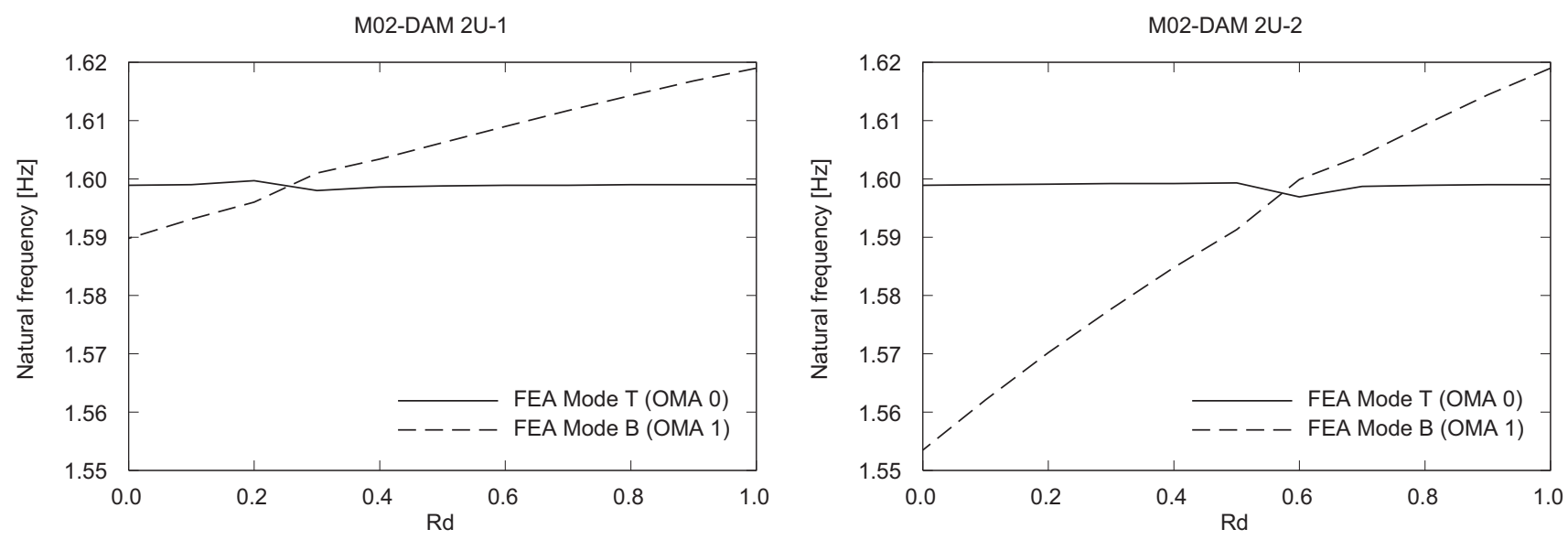

Fig. 13 Effects of damage in the cables on the vibration modes of the bridge. FEA natural frequencies corresponding to OMA modes 0 and 1 , as a function of the damage ratio $R_{d}=A_{\text {cable,dam }} / A_{\text {cable }}$, for the configurations $2 \mathrm{U}-1$ (left) and $2 \mathrm{U}-2$ (right) (ABAQUS/Standard). 
1
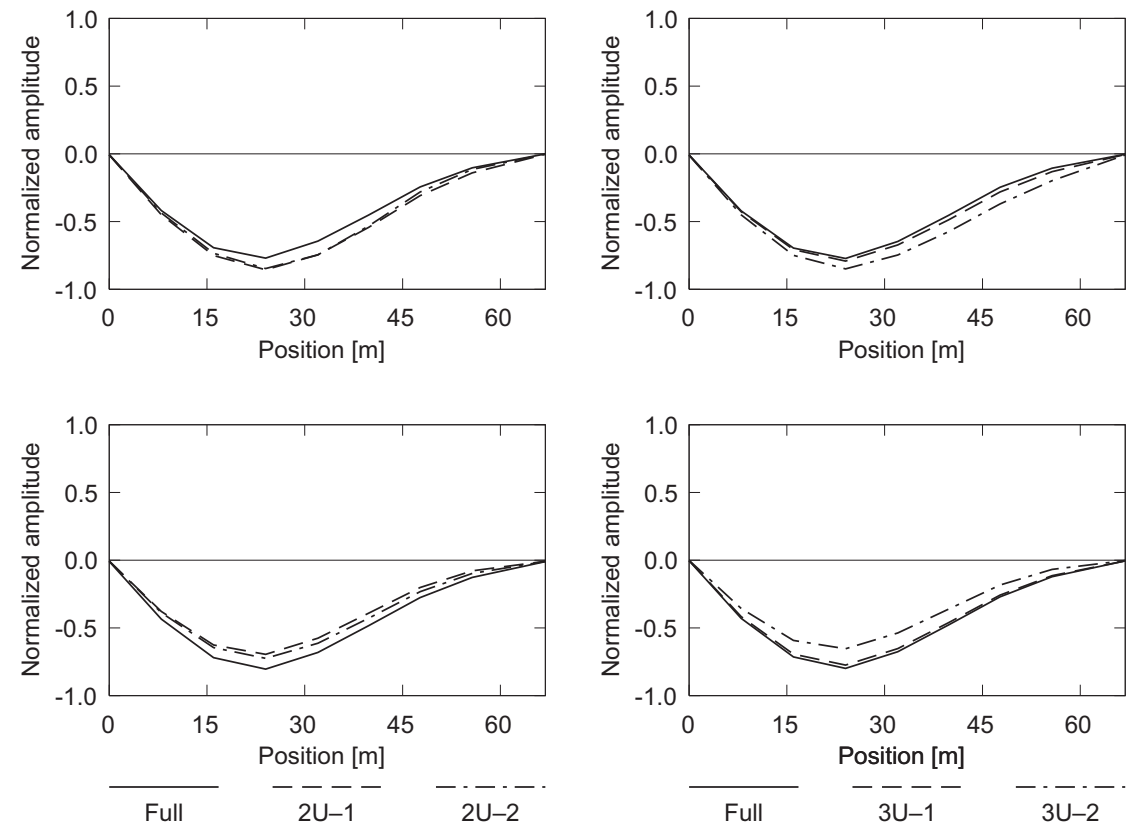

Fig. 14 Effects of damage in the cables on the normalized vibration modes of the bridge. OMA mode 1. Row (a): upstream side; row (b): downstream side (ABAQUS/Standard, Model M02-Full). Left (position 0 m): National Route n.13 side; right (position $67 \mathrm{~m}$ ): Pietratagliata side.

(b)
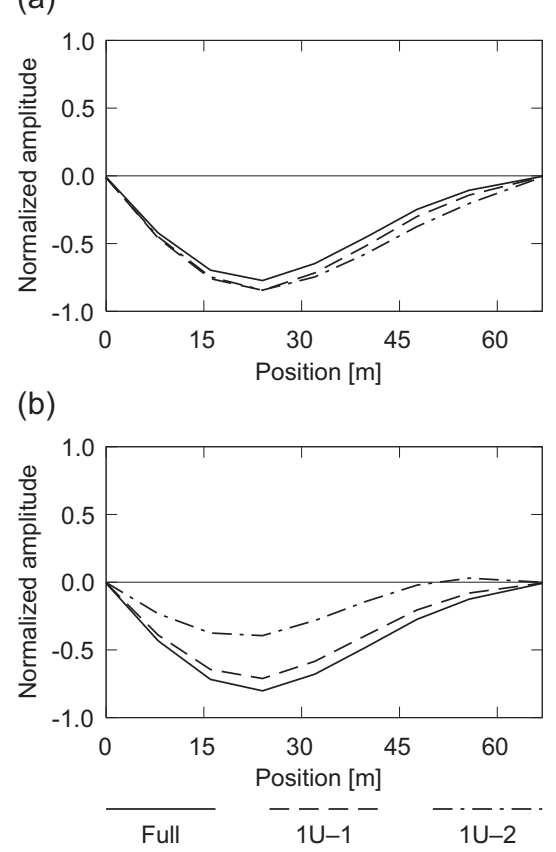
(a)

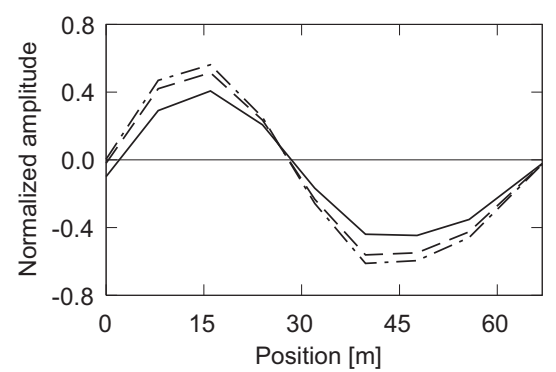

(b)

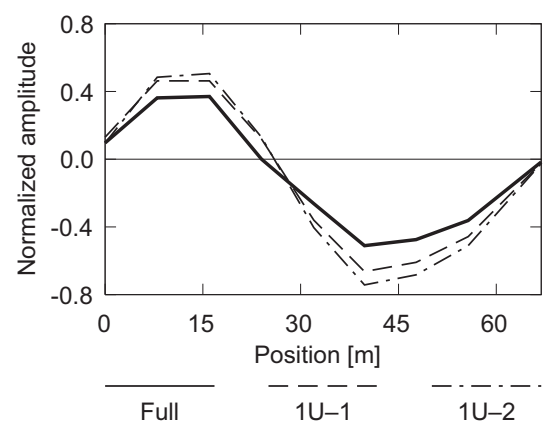

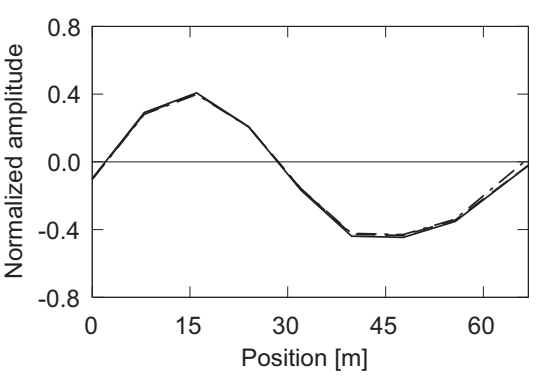

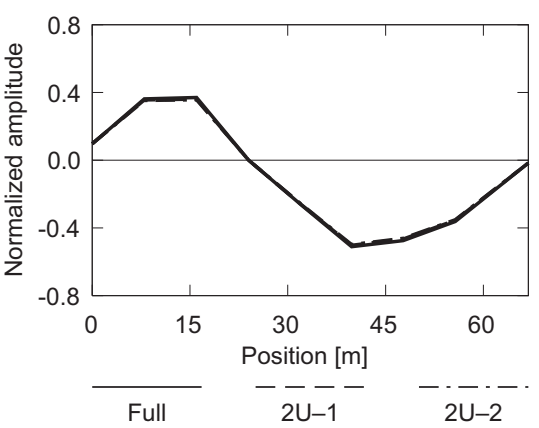

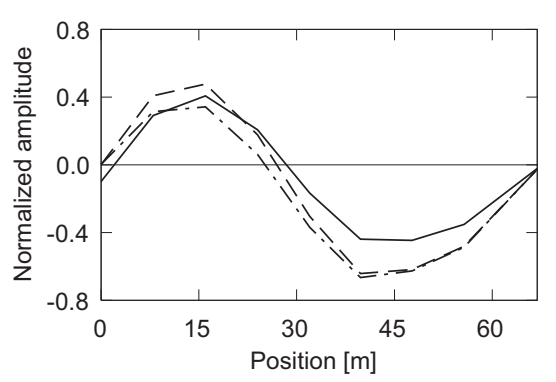

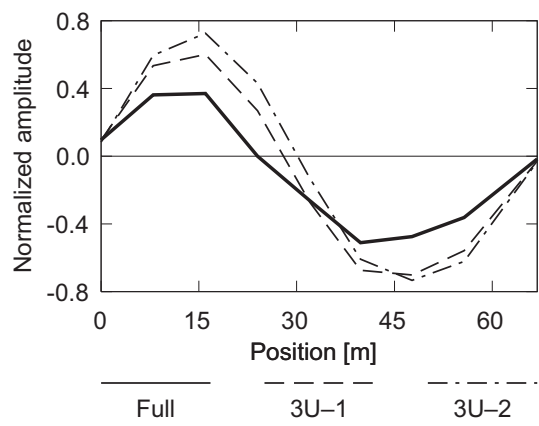

Fig. 15 Effects of damage in the cables on the normalized vibration modes of the bridge. OMA mode 3. Row (a): upstream side; row (b): downstream side (ABAQUS/Standard, Model M02-Full). Left (position 0 m): National Route n.13 side; right (position $67 \mathrm{~m}$ ): Pietratagliata side. 
1

2

3

4

5

6

7

8

9

10

11

12

13

14

15

16

17

18

19

20

21

22

23

24

25

26

27

28

29

30

31

32

33

34

35

36

37

38

39

40

41

42

43

44

45

46

47

48

49

50

51

52

53

54

55

56

57

58

59

60

61

62

63

64

65

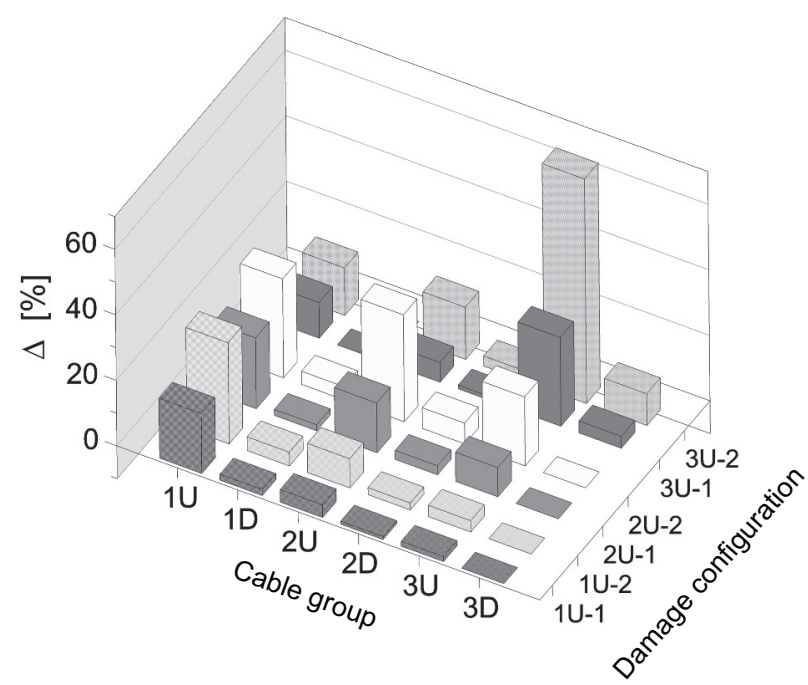

Fig. 16 Effects of damage in the cables on the average axial forces $T$ on each group of stays (ABAQUS/Standard). $\Delta=$ $100 \times\left(T_{M 02-D A M}-T_{M 02}\right) / T_{M 02}$. 
Click here to access/download attachment to manuscript Morassi_Letter.doc 